\title{
Numerical modelling of tsunamis generated by iceberg calving validated with large-scale laboratory experiments
}

\author{
Fan Chen $^{\mathrm{a}, *}$, Valentin Heller ${ }^{\mathrm{a}}$, Riccardo Briganti ${ }^{\mathrm{a}}$ \\ ${ }^{a}$ Environmental Fluid Mechanics and Geoprocesses Research Group, Faculty of \\ Engineering, University of Nottingham NG7 2RD, UK
}

\begin{abstract}
When calving icebergs interact with water, waves of tens of meters in height, so-called iceberg-tsunamis (IBTs), may be generated. Recent examples include an IBT which reached an amplitude of 45 to $50 \mathrm{~m}$ in Eqip Sermia, Greenland, in 2014. A novel numerical methodology and unique large-scale laboratory experiments are presented to investigate the generation and propagation of such IBTs. In the laboratory the IBTs were generated with rigid blocks in a $50 \mathrm{~m} \times$ $50 \mathrm{~m}$ basin. For the numerical model a multiphase flow solver is extended by coupling it with a motion solver to handle dynamic immersed boundaries such as the surfaces of floating icebergs. An analytical solution of the radiated waves by a heaving sphere in still water, a vertically falling and an overturning block experiment are used to validate the numerical model. The model simulates the laboratory IBTs with a maximum relative error of $15.5 \%$ in the first (leading) wave amplitude and $13.8 \%$ in the wave height decay exponent if the splash is ignored. The validated model is then used successfully to replicate the 2014 Eqip Sermia IBT. This new numerical model is expected to be useful for IBT hazard assessment and many further floating body phenomena.
\end{abstract}

Keywords: Fluid-structure interaction, Foam-extend, Iceberg calving, Iceberg-tsunamis, Immersed Boundary Method, Wave decay

\footnotetext{
* Corresponding author

Email address: Fan.chen@nottingham.ac.uk (Fan Chen)
} 


\section{Introduction}

Iceberg calving is the detachment of an iceberg from a larger ice volume such as a glacier or ice sheet. This phenomenon is a major reason for ice mass loss in Greenland and the Antarctica (Benn et al., 2017; Depoorter et al., 2013). When icebergs calve into water, waves of tens of meters in height may be generated (Lüthi and Vieli, 2016). Such waves are called iceberg-tsunamis (IBTs) herein, short for iceberg-generated tsunamis (Heller et al., 2019c; 2020). IBTs are generated by different mechanisms such as fall, overturning and capsizing (Benn et al., 2007; Heller et al., 2019c; 2020). Examples of IBTs in Greenland include a wave which reached an amplitude of 45 to $50 \mathrm{~m}$ at Eqip Sermia in Greenland in 2014 (Lüthi and Vieli, 2016) and a capsizing iceberg causing severe damage in a local harbour in 1995 (Mendsonboaz, 2009). Further, some inhabitants of the village Innaarsuit in Greenland had to be evacuated in July 2018 due to IBT hazards from a floating iceberg (The Guardian, 2018). The potential hazards of such IBTs is further highlighted in Burton et al. (2012), Heller et al. (2019c; 2020), Levermann (2011), Lüthi and Vieli (2016) and MacAyeal et al. (2011).

However, only a few field measurements and experimental studies have been conducted thus far to quantify the generation and propagation of IBTs. Experimental investigations include the small-scale laboratory flume tests of Burton et al. (2012). They estimated that the radiated wave energy and the kinetic energy of the icebergs account for only 1 and $15 \%$ of the total energy released by icebergs, respectively. Heller et al. (2019c; 2020) conducted large-scale experiments in a $50 \mathrm{~m} \times 50 \mathrm{~m}$ wave basin to investigate IBTs involving five idealised iceberg calving mechanisms: (A) capsizing, (B) gravity-dominated fall, (C) buoyancy-dominated fall, (D) gravity-dominated overturning and (E) buoyancydominated overturning. Gravity-dominated masses essentially fall into the water body whereas buoyancy-dominated masses rise to the water surface. Heller et al. (2019c; 2020) found that the total IBT train energy corresponds to 0.6 to $59.6 \%$ of the theoretically released energy from the icebergs over all mechanisms, with 
the remaining energy lost in mechanisms such as bobbing and rocking motions of the block and water system or viscous energy dissipation. Further, Heller et al. (2019c) showed that IBTs generated by mechanisms B and D are typically an order of magnitude larger than tsunamis generated by the remaining three mechanisms. Their experiments were then further analysed by Heller et al. (2019a,b; 2020) to derive empirical equations for the most important IBT features for preliminary hazard assessment.

The aforementioned Eqip Sermia event was investigated in a field study by Lüthi and Vieli (2016). They analysed data from a terrestrial radar interferometer, a tide gauge and a video recorded from a tour boat, resulting most likely in the best documented IBT event ever. They identified an IBT of 45 to $50 \mathrm{~m}$ amplitude near the glacier terminus running-up 10 to $15 \mathrm{~m}$ on the opposite shore, $4 \mathrm{~km}$ from the glacier front. Minowa et al. (2018) recorded 420 calving events at the Perito Moreno glacier in Argentina and found the amplitudes of IBTs to increase with the volume of the iceberg. Vaňková and Holland (2016) investigated IBT propagation through the Sermilik Fjord, Greenland, and measured still a $24 \mathrm{~cm}$ large IBT at a distance of $30 \mathrm{~km}$ from the glacier terminus. They further used the finite-volume method MITgcm model (Marshall et al., 1997) based on the incompressible Navier-Stokes equations, to compute the resonant modes in the fjord and to successfully reproduce the observed IBTs. This appears to be the only numerical simulation of IBTs to date. Given that the numerical options to simulate IBTs are limited, a new flexible and robust numerical model is developed in the present work.

As highlighted in a number of studies (e.g. Benn et al., 2007; Heller et al., 2019a,b,c; 2020; Lüthi and Vieli, 2016; MacAyeal et al., 2011), IBTs are related to landslide-tsunamis, addressed e.g. by Evers and Hager (2016), Heller and Hager (2010), Heller and Spinneken (2015) and Panizzo et al. (2005). Therefore, numerical models capable of reproducing subaerial landslide-tsunamis are also candidates to simulate IBTs. These models include codes based on the Lagrangian as well as the Eulerian approaches.

Lagrangian methods include Smoothed Particle Hydrodynamics (SPH) (e.g. 
Heller et al., 2016; Monaghan and Kos, 2000; Tan et al., 2018; Vacondio et al., 2013). However, wave propagation modelled by SPH can be affected by numerical dissipation (Violeau and Rogers, 2016), requiring coupling with a wave propagation model in the far field, as demonstrated by Abadie et al. (2012), Ruffini et al. (2019) and Tan et al. (2018). The mesh-based Eulerian method is e.g. used in OpenFOAM (Jasak et al., 2007), Thetis (Abadie et al., 2012), REEF3D (Kamath et al., 2016) and $\mathrm{SU}^{2}$ (Palacios et al., 2013). This method is well capable of modelling Fluid-Structure Interactions once the challenges of mesh adaptivity and free surface tracking are overcome. OpenFOAM is a widely used open source mesh-based computational fluid dynamics code containing numerous solvers and utilities to efficiently solve complex fluid problems in coastal and offshore engineering (Jasak 2009).

Handling large displacements of bodies, such as icebergs, and the associated remeshing is a challenging key requirement in the context of IBT generation modelling. The Immersed Boundary Method (IBM) possesses a natural advantage in dealing with this type of problems: the boundary of the moving body is represented by cells in the mesh (Fig. 1), thus the mesh itself does not need to be changed with the movement of the body. The present study uses the IBM of Jasak et al. (2014) who implemented the discrete forcing IBM toolbox in Foam-extend, a fork of OpenFOAM.

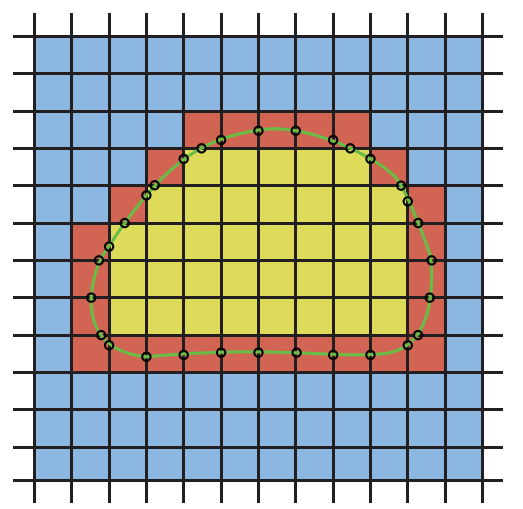

Fluid cell

Solid cell

Immersed boundary cell

- Body boundary

- Intersection of the body boundary and the mesh

Fig. 1 A block modelled with IBM: the boundary of the block is represented by the brown cells in the mesh 
The aim of this work is to set up and validate a numerical model capable of simulating both the generation and propagation of IBTs. A new flow solver and a motion solver (for icebergs) are coupled in Foam-extend based on the IBM toolbox of Jasak et al. (2014). To validate this new approach, the analytical solution of radiated waves from a heaving sphere in still water is used. Given that laboratory tests prior to Heller et al. (2019c; 2020) only involved the capsizing mechanism investigated at very small scale, and given that available field observations do not provide data in a suitable high resolution, results of two large-scale tests of Heller (2019) and Chen and Heller (2020) are also used in the validation process.

Details about the selected large-scale experiments can be found in Section 2 and the numerical model setup is given in Section 3. The validation with the analytical solution of the floating heaving sphere case, convergence tests, a comparison of numerical and laboratory experiments and the simulation of the 2014 Eqip Sermia case are presented in Section 4. The results, with and without turbulence modelling, are discussed in Section 5, along with limitations of the numerical model. The most important conclusions are then presented in Section 6 .

\section{Experimental setup}

Large-scale experiments were conducted in the $50 \mathrm{~m} \times 50 \mathrm{~m}$ large Delta Basin at Deltares in Delft, The Netherlands, with an effective size of $40.3 \mathrm{~m}$ $\times 33.9 \mathrm{~m}$. IBTs were generated by five different iceberg calving mechanisms (Heller et al., 2019c; 2020). Herein, only mechanisms B and D are addressed (Fig. 2). These mechanisms generated the largest measured IBTs, and each of them involves translation or rotation only. Thus, they are well suited to validate the numerical model. An overview of the experimental setup of the selected tests is provided here, with full details being given by Heller (2019).

A block made of polypropylene homopolymer with a density $\rho_{s} \approx 920 \mathrm{~kg} / \mathrm{m}^{3}$ was used to mimic the iceberg which was supported by a purpose-built steel 
(a) Gravity-dominated fall

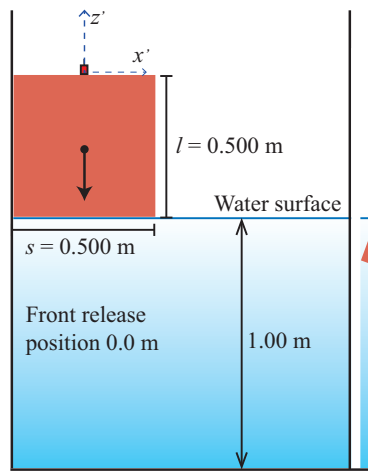

(b) Gravity-dominated overturning

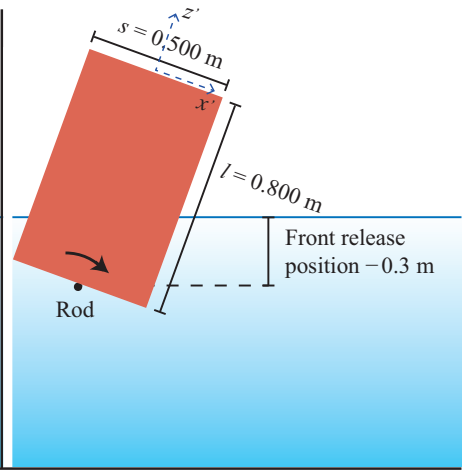

Fig. 2 Illustration of the two iceberg calving mechanisms applied herein:

(a) gravity-dominated fall and (b) gravity-dominated overturning

(adapted from Heller et al., 2019c)

frame at the basin wall. For mechanism B, the block was held in position with an electromagnet prior to release, which was attached to a small steel plate integrated into the block. For mechanism D, the rotation of the block was initiated by removing the safety mechanism and simply by letting the block go. It rotated around a fixed axis defined with a steel rod of $30 \mathrm{~mm}$ diameter (Fig. 2b). This rod was fed through two ball bearings fixed to the block bottom surface, and held in position on both sides with profiles rigidly connected to the steel frame. The block performed therefore a pure rotational motion (Heller, 2019).

Fig. 3(a) shows a side view of the mechanism B experiment. The water depth $h$ was $1.00 \mathrm{~m}$ and the basin bottom was horizontal. The block length $l$, width $b$ and thickness $s$ were $0.500 \mathrm{~m} \times 0.800 \mathrm{~m} \times 0.500 \mathrm{~m}$ in mechanism B and 0.800 $\mathrm{m} \times 0.500 \mathrm{~m} \times 0.500 \mathrm{~m}$ in mechanism $\mathrm{D}$, and it weighted $187.1 \mathrm{~kg}$ including the $2.5 \mathrm{~kg}$ heavy steel plate. The front release position in Fig. 2 corresponds to the distance of the bottom face of the block from the still water surface in each of the cases tested.

The IBT features were measured with 35 resistance-type wave probes with a sampling frequency of $100 \mathrm{~Hz}$ with an estimated accuracy of $\pm 0.1 \mathrm{~mm}$. They were placed in a quarter circle as shown in Fig. 3(b), given that the wave field is symmetric relative to the block axis. A cylindrical coordinate system $(r, z, \gamma)$ 
is adopted with the origin located at the steel frame centre on the water surface (Fig. 3). $r$ is the radial distance from the origin, the $z$-axis points upwards and the wave propagation angle $\gamma$ is defined positive in clockwise direction. The locations of the wave probes are shown in Table 1, together with the location of the $5 \mathrm{MP}$ camera used for general observations. A low-pass filter with a cut-off frequency between 9 and $11 \mathrm{~Hz}$ was applied to remove noise in the wave probe data. The experimental data collected by means of the wave probes, camera and the motion sensor were synchronised to work with a common starting point. Synchronisation between two independently triggered systems (a) including the wave probes and camera and (b) involving the motion sensor and electromagnet was achieved by a synchronisation pulse generated by system (a) which was recorded by the LabView programme controlling system (b).

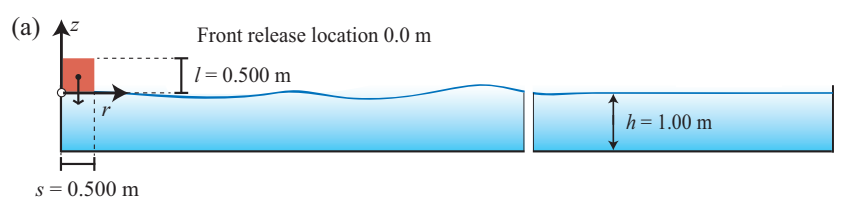

(b)

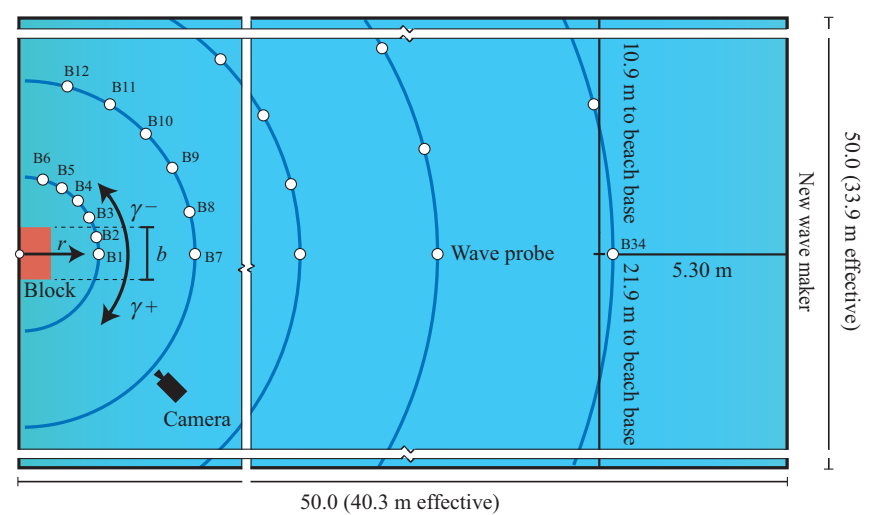

Fig. 3 (a) Side and (b) plan view of the mechanism B experiment (adapted from Heller et al., 2020)

A 9-Degrees of Freedom (DoF) motion sensor was fixed on the top face of the blocks to record the block kinematics. A global Cartesian coordinate system ( $x$, $y, z)$ is used here with the same origin and $z$-axis as the cylindrical coordinate system. The $x$-axis is directed along $\gamma=0^{\circ}$ and the $y$-axis along $\gamma=-90^{\circ}$ 
(Fig. 3). The origin of a local coordinate system $\left(x^{\prime}, y^{\prime}, z^{\prime}\right)$ is located at the centre of the motion sensor (Fig. 2). The axes of the local and global coordinate systems are parallel before block movement, and the local coordinate system translates or rotates then along with the motion sensor. The 9-DoF motion sensor measured accelerations along three local axes (Fig. 2), three global angles and three components from the Earth's geomagnetic field. Only the first six DoF were required to extract the block velocity and position. The trajectory inference method to extract the block velocity and position based on the 9-DoF motion sensor is described in Appendix A.

Table 1 Locations of the wave probes and camera of both mechanisms B and D in the laboratory experiments. Values marked with * were also used in the numerical basin (adapted from Heller, 2019)

\begin{tabular}{|c|c|}
\hline Device & $\begin{array}{l}\text { Locations in function of the radial distance } \\
r(\mathrm{~m}) \text { and wave propagation angle } \gamma\left({ }^{\circ}\right) \\
(\text { Fig. 3a and b) }\end{array}$ \\
\hline $\begin{array}{c}\text { Wave } \\
\text { probes }\end{array}$ & $\begin{array}{l}\mathrm{B} 1(2,0)^{*} ; \mathrm{B} 7(3,0)^{*} ; \mathrm{B} 13(5,0)^{*} ; \mathrm{B} 19(10,0) ; \mathrm{B} 25(15,0) ; \mathrm{B} 31(22.5,0) ; \\
\mathrm{B} 34(35,0) ; \\
\mathrm{B} 2(2,-15)^{*} ; \mathrm{B} 8(3,-15)^{*} ; \mathrm{B} 14(5,-15)^{*} ; \mathrm{B} 20(10,-15) ; \mathrm{B} 26(15,-15) ; \\
\mathrm{B} 32(22.5,-15) ; \mathrm{B} 35(35,-15) ; \\
\mathrm{B} 3(2,-30)^{*} ; \mathrm{B} 9(3,-30)^{*} ; \mathrm{B} 15(5,-30)^{*} ; \mathrm{B} 21(10,-30) ; \mathrm{B} 27(15,-30) ; \\
\mathrm{B} 33(22.5,-30) ; \\
\mathrm{B} 4(2,-45)^{*} ; \mathrm{B} 10(3,-45)^{*} ; \mathrm{B} 16(5,-45)^{*} ; \mathrm{B} 22(10,-45) ; \mathrm{B} 28(15,-45) ; \\
\mathrm{B} 5(2,-60)^{*} ; \mathrm{B} 11(3,-60)^{*} ; \mathrm{B} 17(5,-60)^{*} ; \mathrm{B} 23(10,-60) ; \mathrm{B} 29(15,-60) ; \\
\mathrm{B} 6(2,-75)^{*} ; \mathrm{B} 12(3,-75)^{*} ; \mathrm{B} 18(5,-75)^{*} ; \mathrm{B} 24(10,-75) ; \mathrm{B} 30(15,-75)\end{array}$ \\
\hline Camera & $(6,45)$ \\
\hline
\end{tabular}

\section{Numerical model}

The numerical model is based on Foam-extend 4.0 (OpenFOAM extensions, 2016), including the IBM toolbox from Jasak et al. (2014). To simulate both the generation and propagation of IBTs, a new flow solver and a modified motion solver were implemented in Foam-extend within this work. The new features are introduced in this section together with the coupling method and a description of the numerical domain.

The same global coordinate system $(x, y, z)$ as in Section 2 is applied. The numerical wave basin, shown in Fig. 4, consists of the IBT generation (zone A) 
and propagation (zone B) zones. The dimensions of zone A are $1.0 \mathrm{~m} \times 1.0 \mathrm{~m}$ $\times 1.7 \mathrm{~m}$ and its centre is $9.0 \mathrm{~m}$ away from the basin side wall. The length and width of zone B are 15.0 and $18.0 \mathrm{~m}$, respectively, excluding zone A. The total height of zone B is $1.2 \mathrm{~m}$ with a $0.2 \mathrm{~m}$ thick air layer above the water surface. The cell dimensions in the $x, y$ and $z$ directions in zone $\mathrm{A}$ are identical, while in zone B they vary in some convergence tests.

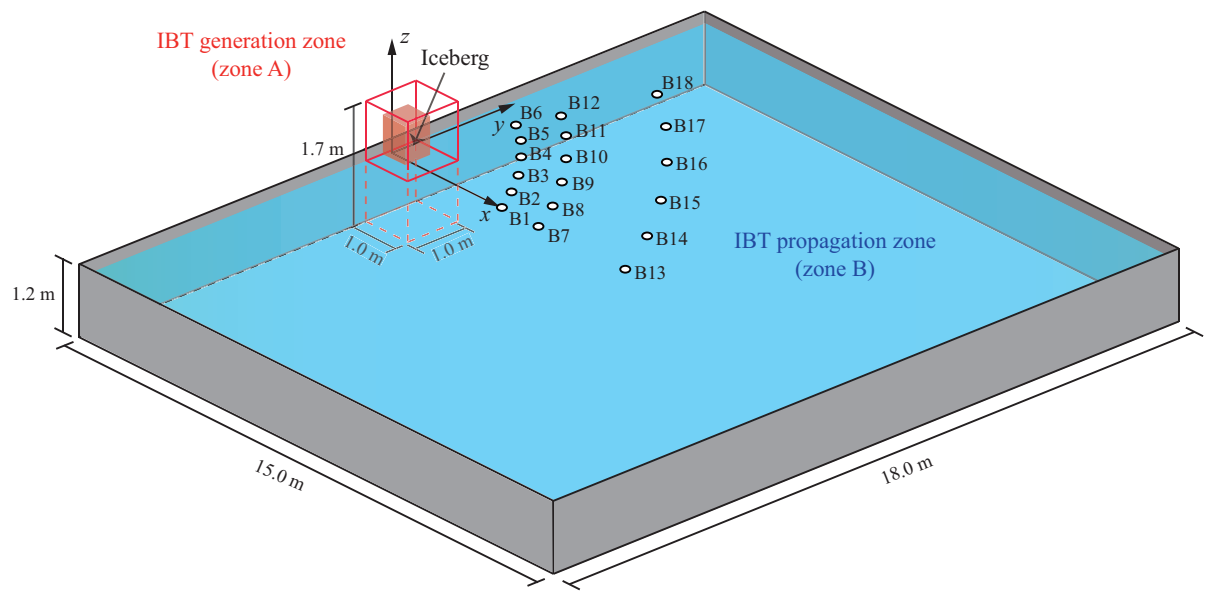

Fig. 4 Sketch of the numerical wave basin with the IBT generation and propagation zones including the wave probe locations. The red frame marks zone A

\subsection{Flow solver}

The new solver interDyMIbFoam was implemented within this work based on the already provided solver interIbFoam for two incompressible fluids (water and air) with IBM support in Foam-extend 4.0. In contrast to interIbFoam based on a static mesh, the new solver interDyMIbFoam can handle dynamic immersed boundaries in order to describe various types of motion of moving bodies including icebergs.

InterDyMIbFoam solves the Reynolds-Averaged Navier Stokes (RANS) equations using the finite volume method based on the Carthesian coordinate system $(x, y, z)$ shown in Fig. 4 . The two governing equations for both viscous Newtonian fluids water and air are

$$
\nabla \cdot \mathbf{u}=0
$$




$$
\frac{\partial \mathbf{u}}{\partial t}+(\mathbf{u} \cdot \nabla) \mathbf{u}=-\frac{1}{\rho} \nabla p+\frac{\mu+\mu_{t}}{\rho} \nabla^{2} \mathbf{u}+\frac{1}{\rho} \mathbf{g} .
$$

In Eqs. (1) and (2) $\mathbf{u}=\left(u_{x}, u_{y}, u_{z}\right)$ is the fluid velocity vector, $p$ the pressure, $\nabla=\left(\frac{\partial}{\partial x}, \frac{\partial}{\partial y}, \frac{\partial}{\partial z}\right)$ the differential operator, $\mathbf{u} \cdot \nabla=u_{x} \frac{\partial}{\partial x}+u_{y} \frac{\partial}{\partial y}+u_{z} \frac{\partial}{\partial z}$ the dot product, $\rho$ denotes the density, $\mu$ the dynamic viscosity, $\mu_{t}$ the turbulent viscosity ( $\mu_{t}=0$ in the laminar model) and $\mathbf{g}$ the gravitational acceleration vector. The Volume of Fluid method is applied to track the interface between the two fluids. The phase fraction $0 \leq \alpha \leq 1$ is introduced with $\alpha=1$ denoting one fluid (water), $\alpha=0$ the other one (air) and $0<\alpha<1$ the interface. The physical parameters such as $\rho$ and $\mu$ of the two fluids are then evaluated in function of $\alpha$ as

$$
\rho=\rho_{w} \alpha+\rho_{a}(1-\alpha)
$$

$$
\mu=\mu_{w} \alpha+\mu_{a}(1-\alpha)
$$

where the subscripts $w$ and $a$ denote water and air, respectively. Once the velocity field is obtained, $\alpha$ can be updated over time by solving the transport equation

$$
\frac{\partial \alpha}{\partial t}+\nabla \cdot(\alpha \mathbf{u})+\nabla \cdot[\alpha(1-\alpha) \mathbf{u}]=\mathbf{0} .
$$

The term $\nabla \cdot[\alpha(1-\alpha) \mathbf{u}]$ in Eq. (5) is used to sharpen the air-water interface (Weller et al., 1998).

Fig. 5 shows the steps applied in the interDyMFoam solver. When the solver is executed, a small initial time step $\Delta t^{1}$ is set. The time step is then controlled by the Courant-Friedrichs-Lewy number. The forces on the iceberg are calculated for each time step before the motion solver is called to determine the new position of the iceberg. The immersed boundary is updated by regenerating the immersed boundary mask (Jasak et al., 2014). Thereafter, governed by the PIMPLE loop, which is a combination of Pressure Implicit with Splitting of Operator (PISO) and Semi-Implicit Method for Pressure-Linked Equations (SIMPLE) algorithms, interDyMIbFoam solves the velocity and pressure equations to obtain the velocity and pressure fields successively. Then Eq. (5) is 
213

used to update the current interface between the two fluids (Fig. 5). Finally, a turbulence correction function can be called for each time step if turbulence is included in the simulation.

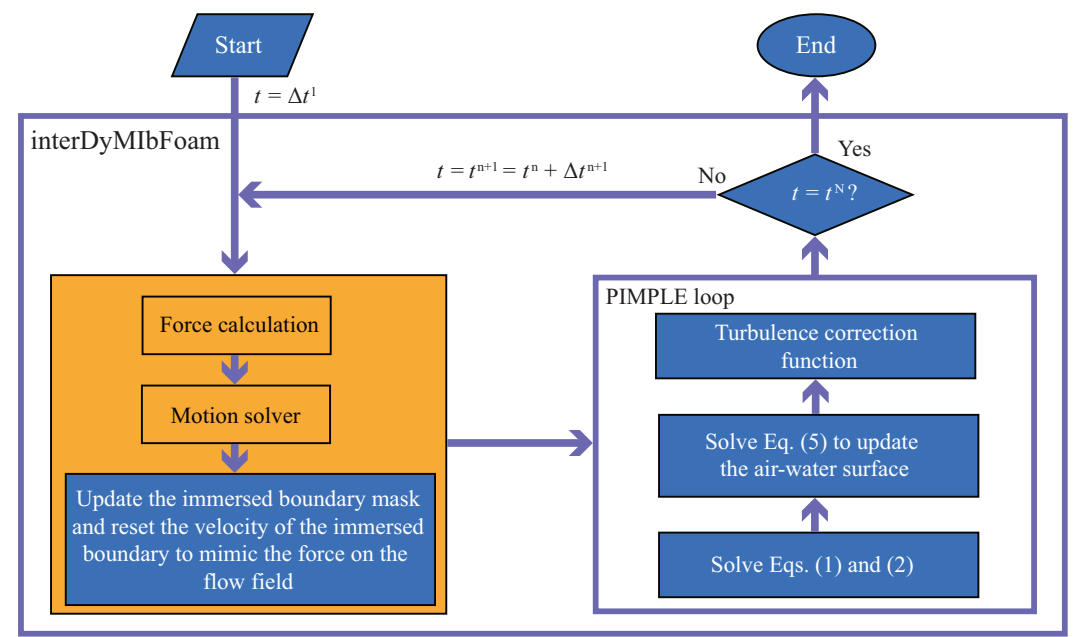

Fig. 5 Steps applied in the interDyMIbFoam solver added to Foam-extend (the orange boxes denote new implementations or modifications in this work, while blue boxes denote previously available functions)

\subsection{Motion solver}

In the numerical model, the icebergs can translate, rotate or perform a combination of the two. When using the motion solver, all motions are flow-induced rather than prescribed. The equations of motion for the iceberg are given as

$$
\mathbf{a}=\frac{\mathbf{F}}{m_{s}}
$$

$$
\xi=\frac{\mathbf{M}}{I}
$$

where $\mathbf{a}$ and $\xi$ are the acceleration and angular acceleration vectors, respectively. $\mathbf{F}$ is the total force vector acting on the iceberg. $\mathbf{M}$ is the total torque in relation to the centre of rotation, $I$ the moment of inertia and $m_{s}$ denotes the mass of the iceberg. The approach to calculate $\mathbf{F}$ followed here is commonly used in the modelling of dynamics of floating bodies (Newman, 2018): the added mass and drag force coefficients appear explicitly in the momentum equation. The same 
approach was used for the modelling of submerged landslides in Grilli and Watts (2005) and Enet and Grilli (2007). Given the strong analogy between landslidetsunamis and IBTs, this was deemed suitable for the problem at hand. Further, although the derivation of the drag forces from the flow characteristics is possible (Mei, 1989), the approach by Enet and Grilli (2007) has been applied because of its simplicity in allowing the derivation of the drag force when experimental cases are analysed. An alternative approach is followed by Hadžić et al. (2005), in which the flow equations are solved directly, i.e. without explicit added mass and friction coefficients. However, an under-relaxation technique was used and this was deemed equivalent to introducing the added mass in Eq. (19) in Hadžić et al. (2005). Therefore, $\mathbf{F}$ is defined as

$$
\mathbf{F}=\mathbf{F}_{p}+\mathbf{F}_{v}+\mathbf{F}_{d}-m_{a} \mathbf{a}+\mathbf{G}
$$

where $\mathbf{F}_{p}$ is the pressure force, $\mathbf{F}_{v}$ the viscosity force caused by the two fluids, $\mathbf{F}_{d}$ the drag force, $-m_{a} \mathbf{a}$ the virtual force caused by the added mass $m_{a}$ and $\mathbf{G}$ is the gravity force. Only these force terms are considered in the calculation of $\mathbf{M}$. Details about the calculation of $\mathbf{F}$ and $\mathbf{M}$ are given in Section 3.3. Once $\mathbf{a}$ and $\xi$ are calculated, the velocity vector of the centre of mass $\mathbf{v}_{C o M}$ and the angular velocity of the centre of rotation of the iceberg $\omega_{C o R}$ can be obtained after one, and the position vector of the centre of mass of the iceberg $\mathbf{X}_{C o M}$ and the iceberg rotation angle vector $\boldsymbol{\theta}_{C o R}$ after two integrations of a and $\boldsymbol{\xi}$ with respect to time. The location of the centre of mass of the iceberg is only used as a reference for determining the displacement of the block. In this work, the motion solver is modified based on the already provided solver sixDoFMotion, where a leapfrog scheme with second-order accuracy based on Dullweber et al. (1997) is applied to update the position $\left(\mathbf{X}_{C o M}\right.$ and $\left.\boldsymbol{\theta}_{C o R}\right)$ and velocity $\left(\mathbf{v}_{C o M}\right.$ and $\left.\boldsymbol{\omega}_{C o R}\right)$ successively for each time step.

Some restrictions for the DoFs are required based on the laboratory conditions. These are applied by imposing the moment and force components to zero at each time step for the translational and rotational motion, respectively. 
Moreover, only the relevant acceleration and angular acceleration components are used in Eqs. (6) and (7).

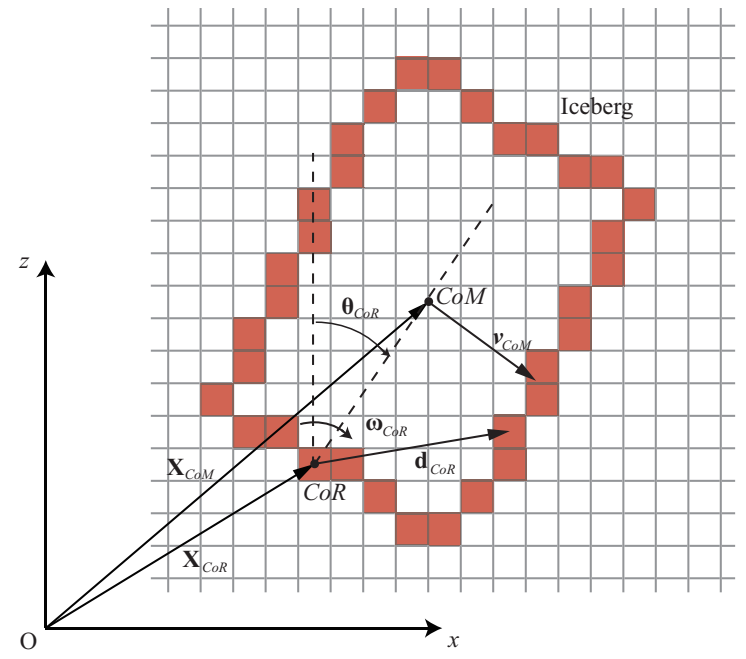

Fig. 6 Sketch of vectors used in Eqs. (11) and (12) involving the mechanism D test. The brown cells denote the immersed boundary of the iceberg

\subsection{Coupling method}

Coupling the flow and motion solvers requires data exchange. This is achieved with a new dynamic mesh handling class in Foam-extend, via which the velocity and pressure field data are read and used to calculate the new force. In turn, the new position of the immersed boundary may change the velocity and pressure fields.

$\mathbf{F}_{p}$ and $\mathbf{F}_{v}$ are directly calculated using data of the velocity gradient and pressure fields at each time step. $\mathbf{F}_{d}$ and $m_{a}$ are given by Enet and Grilli (2007) as

$$
\mathbf{F}_{d}=-\frac{1}{2} C_{d} \rho_{s} A_{b} v_{C o M}\left|v_{C o M}\right|
$$

$$
m_{a}=C_{m} m_{s}
$$

where $C_{d}$ is the drag force coefficient, $A_{b}$ the iceberg's cross section perpendicular to the direction of velocity and $C_{m}$ the added mass coefficient. The selection of the values of $C_{d}$ and $C_{m}$ is discussed in Section 4.4. Therefore, $\mathbf{F}$ and $\mathbf{M}$ in 
Eqs. (6) and (7) are calculated with

$$
\begin{aligned}
& \mathbf{F}=\mathbf{F}_{p}+\mathbf{F}_{v}+\mathbf{F}_{d}-m_{a} \mathbf{a}+\mathbf{G} \\
& =\Sigma\left(p_{i b} \cdot \mathbf{S}_{i b}\right)+\Sigma\left(\tau_{i b} \cdot \mathbf{S}_{i b}\right)-\frac{1}{2} C_{d} \rho_{s} A_{b} v_{C o M}\left|v_{C o M}\right|-C_{m} m_{s} \mathbf{a}+m_{s} \mathbf{g} \\
\mathbf{M}=\Sigma\left[\mathbf{d}_{C o R} \times\left(p_{i b} \cdot \mathbf{S}_{i b}\right)\right]+\Sigma\left[\mathbf{d}_{C o R} \times\left(\tau_{i b} \cdot \mathbf{S}_{i b}\right)\right] & -\left(\mathbf{X}_{C o M}-\mathbf{X}_{C o R}\right) \times \frac{1}{2} C_{d} \rho_{s} A_{b} v_{C o M}\left|v_{C o M}\right|-\left(\mathbf{X}_{C o M}-\mathbf{X}_{C o R}\right) \times C_{m} m_{s} \mathbf{a} \\
+ & \left(\mathbf{X}_{C o M}-\mathbf{X}_{C o R}\right) \times m_{s} \mathbf{g} .
\end{aligned}
$$

The vectors used in the force and torque calculations are shown in Fig. 6. In Eqs. (11) and (12) $\mathbf{S}_{i b}$ denotes the vector of the immersed boundary cell area and $\tau_{i b}$ is the shear stress along the immersed boundary cell that is calculated by multiplying the immersed boundary (subscript $i b$ ) cell's dynamic viscosity by its velocity gradient. In Eq. (12), $\mathbf{d}_{C o R}$ is the vector pointing from the immersed boundary cell to the centre of rotation and $\mathbf{X}_{C o R}$ is the position vector of the centre of rotation of the iceberg. By passing the force and torque data to the motion solver, the new position of the immersed boundary can be calculated. According to the no-slip condition, the updated moving immersed boundary mimics the effect of the force from the iceberg on the fluids. Then the PIMPLE loop is applied (Fig. 5).

\section{Results}

The presented results include the validation of the numerical model with an analytical solution of radiated waves from a floating heaving sphere. An overview of IBT generation in the laboratory tests is then given using snapshots from the experiments, followed by convergence tests with prescribed iceberg motion and a comparison of the numerical and laboratory IBTs for resolved iceberg motion. Finally, this numerical model is used to simulate the 2014 Eqip Sermia case.

\subsection{Validation with the radiated waves from a floating heaving sphere}

The theoretical floating heaving sphere case of Hulme (1982) is used to validate the numerical model. The geometry of the mathematical problem is shown 
in Fig. 7. A spherical polar coordinate system is adopted with $z=0$ corresponding to the still water surface and also the top face of the hemisphere. This floating hemisphere with a radius $a_{r}$ performs a vertical oscillation at the angular frequency $\sigma$ and a velocity of $V_{z}=A \cos (\sigma t)$, with the oscillation amplitude $A=1 \mathrm{~m}$. The surrounding water has an infinite depth and is assumed to be incompressible, inviscid with irrotational motion. The governing equations and boundary conditions for this problem are the continuity equation, a free surface condition, radiation equations and boundary conditions on the body surface. Note that only the last condition depends on the geometry of the body. When the hemisphere undergoes an oscillation with small amplitude relative to $a_{r}$, the body surface boundary condition given by Eq. (2.5) in Hulme (1982) can be assumed to be the same as for the full sphere case. Therefore, a full sphere is applied with the corresponding velocity potential $\Phi$ of the surrounding water given as

$$
\Phi=\operatorname{Re}\left\{C a_{r}^{2}\left[\phi_{0}+\sum_{i=1}^{\infty} p_{\mathrm{i}}^{0} a_{r}^{2 \mathrm{i}} \phi_{\mathrm{i}}\right] e^{-i \sigma t}\right\}
$$

In Eq. (13) $C$ and $p_{\mathrm{i}}$ are the unknown complex constants and $\phi_{0}$ and $\phi_{\mathrm{i}}$ denote the wave source and wave-free potentials, respectively. Based on linear wave theory, the water surface elevation $\eta$ is obtained as

$$
\eta=-\frac{1}{g} \frac{\partial \Phi}{\partial t}
$$

Details about the solutions of $p_{\mathrm{i}}, C$ and $\Phi$ can be found in Appendix B.

The numerical basin of $12.0 \mathrm{~m} \times 12.0 \mathrm{~m} \times 3.2 \mathrm{~m}$ is shown in Fig. 8. The floating sphere with a radius of $a_{r}=0.25 \mathrm{~m}$ is placed at the centre of the basin. A $0.2 \mathrm{~m}$ thick air layer is located above the water surface extending to $0.5 \mathrm{~m}$ in the wave generation zone (Fig. 8). A cell dimension of $0.02 \mathrm{~m} \times 0.02 \mathrm{~m} \times$ $0.02 \mathrm{~m}$ was chosen. The computational domain consisted of 57,662,500 cells and the simulation of $8.0 \mathrm{~s}$ required approximately $36 \mathrm{~h}$ with 144 cores on an HPC cluster. In order to satisfy linear wave theory, a small oscillation amplitude of the sphere was prescribed as $z=0.06 \sin (\sigma t+\pi)$ with $\sigma=4.72 \mathrm{rad} / \mathrm{s}$. The ratio 


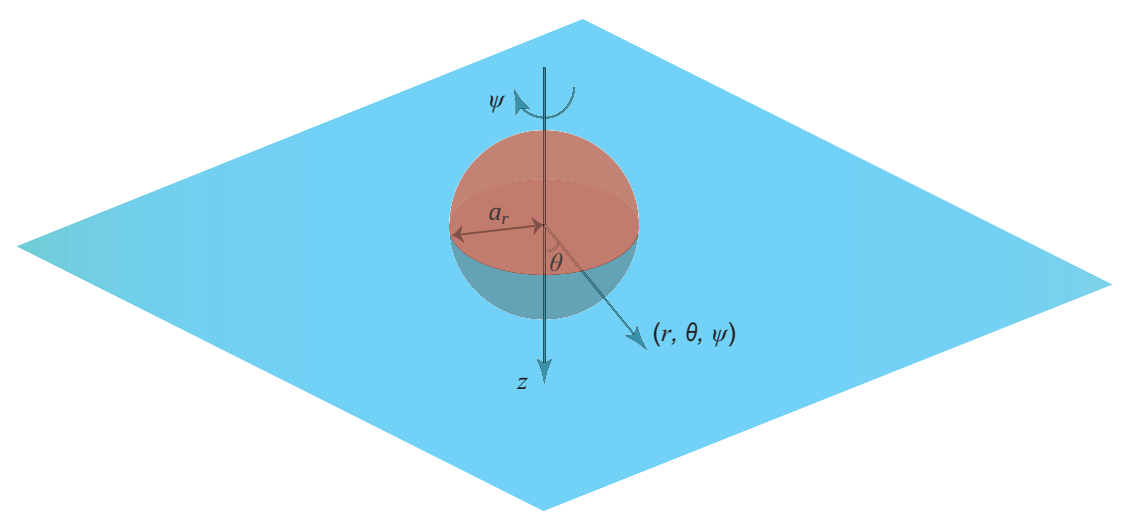

Fig. 7 Sketch defining the parameters for the mathematical problem of a heaving sphere (adapted from Hulme, 1982)

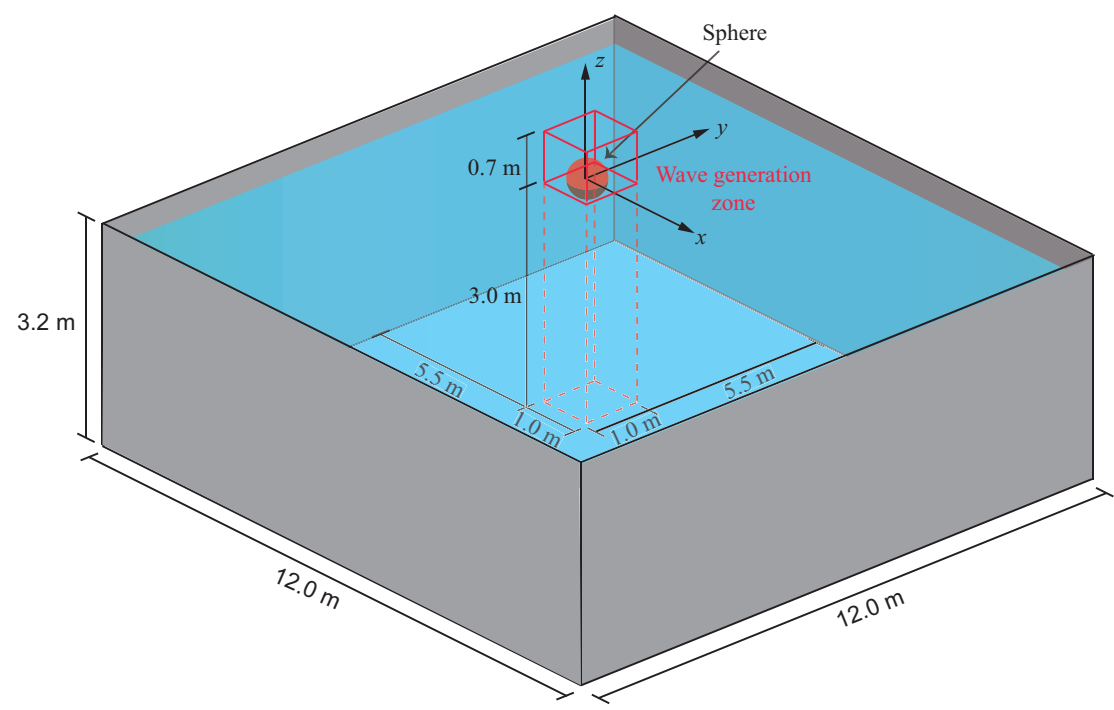

Fig. 8 Sketch of the numerical wave basin of the theoretical heaving sphere case

Fig. 9 shows the comparison of the simulated free water surface $\eta$ at $r=1.0$ and $3.0 \mathrm{~m}$ with the corresponding analytical solution. The analytical solution is asymptotic, while the numerical solution is transient as the waves are gradually generated. Note that the numerical results affected by reflection are excluded in this work. The arrival time of the first reflected wave was calculated based on 
the wave celerity and the travel distance of the wave front from the measurement location to the boundary and back. The normalised Root Mean Square Error (nRMSE) is given by

$$
\mathrm{nRMSE}=\frac{\sqrt{\frac{\sum_{\mathrm{i}=t_{1}}^{t_{\mathrm{N}}}\left(\eta_{\text {analytical }, \mathrm{i}}-\eta_{\text {numerical }, \mathrm{i}}\right)^{2}}{\mathrm{~N}}}}{\eta_{\text {analytical }, \text { max }}-\eta_{\text {analytical }, \text { min }}} .
$$

The

21

1 (1) sis (1) the
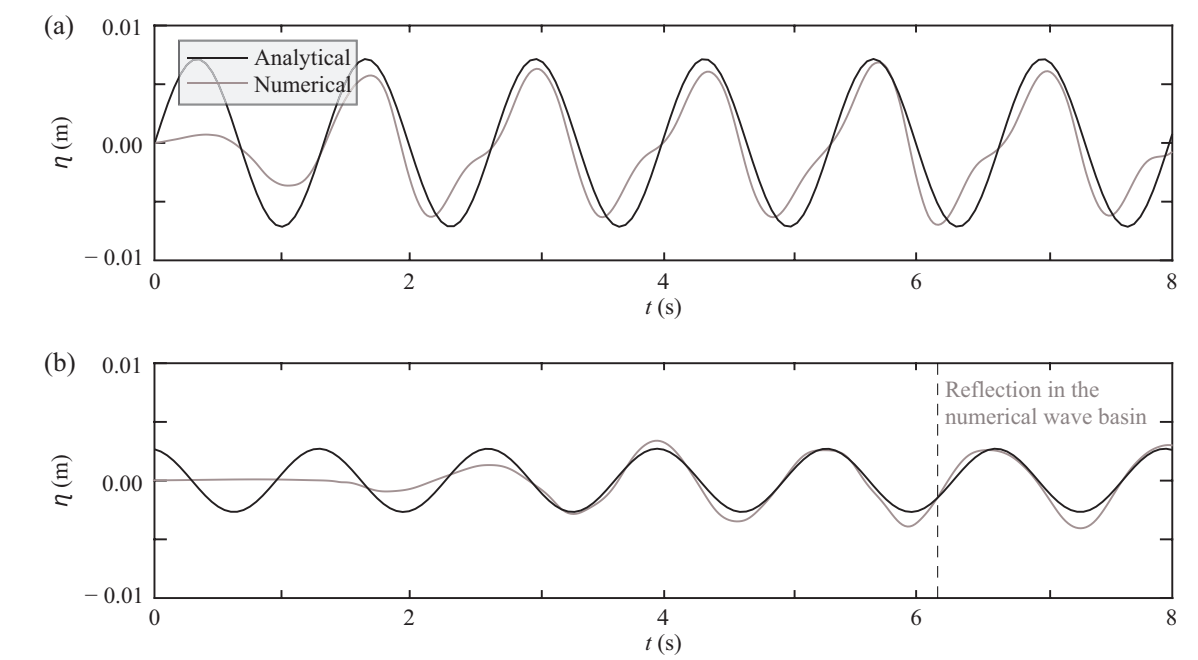

Fig. 9 Numerical and analytical water surface elevations $\eta(t)$ at (a) $r=1.0 \mathrm{~m}$ and (b) $r=$ $3.0 \mathrm{~m}$ (for legend see a)

\subsection{Overview of IBTs in the laboratory tests}

Snapshots of IBTs generated by mechanisms B and D in the laboratory are shown in Figs. 10 and 11, respectively, with $1.33 \mathrm{~s}$ time intervals between the frames. For mechanism B (Fig. 10), the block is released at $t=0.00 \mathrm{~s}$, falls 
vertically and is fully submerged at $1.33 \mathrm{~s}$. A splash together with the first two waves can be seen in Fig. 10(b). At $t=2.67 \mathrm{~s}$, the block is more submerged and the radiated waves continue to propagate in a semi-circular pattern. The block moves then upwards, and the top face of the block reaches the water surface at $t=4.00 \mathrm{~s}$.

(a)

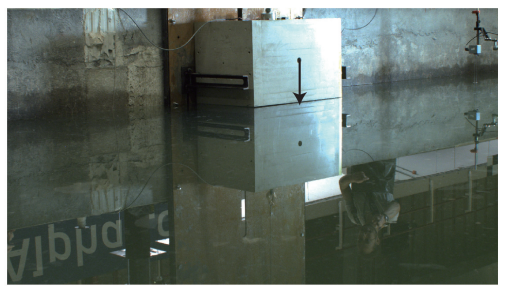

(c)

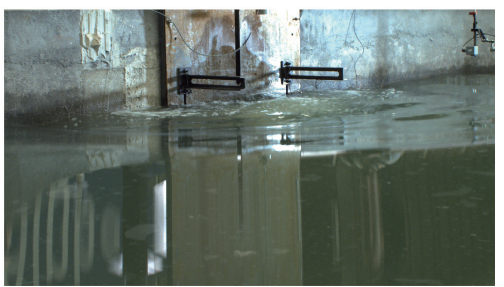

(b)

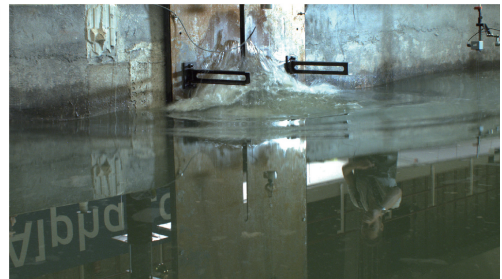

(d)

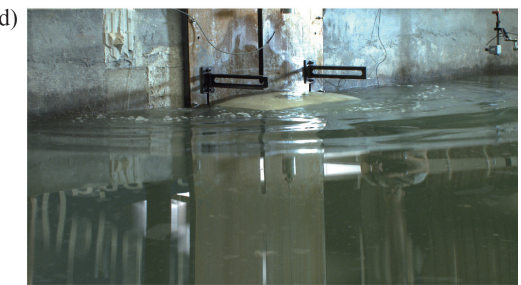

Fig. 10 Snapshots of IBTs in the laboratory generated by mechanism B at (a) $t=0.00 \mathrm{~s}$, (b) $t=1.33 \mathrm{~s}$, (c) $t=2.67 \mathrm{~s}$ and (d) $t=4.00 \mathrm{~s}$

(a)

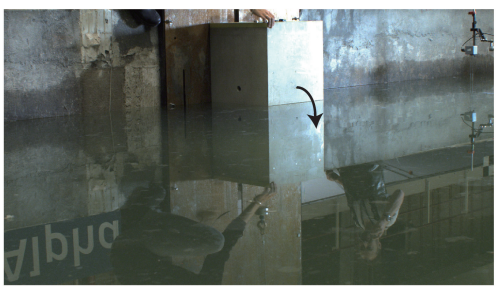

(c)

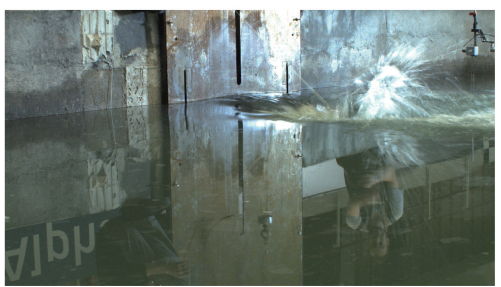

(b)

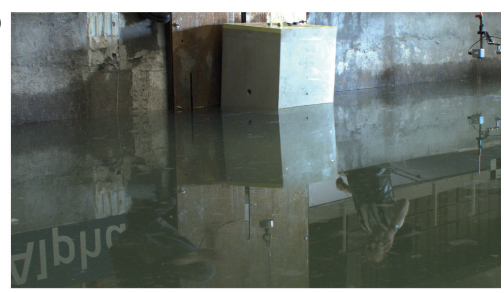

(d)

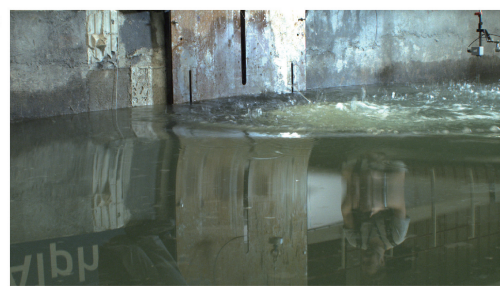

Fig. 11 Snapshots of IBTs in the laboratory generated by mechanism D at (a) $t=0.00 \mathrm{~s},(\mathrm{~b})$ $t=1.33 \mathrm{~s}$, (c) $t=2.67 \mathrm{~s}$ and (d) $t=4.00 \mathrm{~s}$

For mechanism D (Fig. 11), the block starts to overturn at $t=0.00 \mathrm{~s}$, which 
is still ongoing at $1.33 \mathrm{~s}$. The block is fully submerged at $t=2.67 \mathrm{~s}$ and causes a large splash in the main wave generation direction shown in Fig. 11(c). The block front moves then back upwards to the water surface but is still submerged at $t=4.00 \mathrm{~s}$.

\subsection{Convergence tests with prescribed motion}

For the convergence tests for mechanism B, the block was directly located at the basin back wall (Fig. 4). However, for mechanism D, the block had to be two cell widths away from the back wall for the solver to recognise the immersed boundary and to accommodate rotation. This is likely to affect the wave magnitude as discussed in Section 4.6. Three resolutions in zone A (Fig. 4) were considered namely $0.020 \mathrm{~m}, 0.025 \mathrm{~m}$ and $0.050 \mathrm{~m}$ in all three directions. In zone B four different resolutions namely $0.050 \mathrm{~m} \times 0.050 \mathrm{~m} \times 0.050 \mathrm{~m}$, $0.050 \mathrm{~m} \times 0.025 \mathrm{~m} \times 0.025 \mathrm{~m}, 0.025 \mathrm{~m} \times 0.025 \mathrm{~m} \times 0.025 \mathrm{~m}$ and $0.020 \mathrm{~m} \times$ $0.020 \mathrm{~m} \times 0.020 \mathrm{~m}$ were investigated. The resolution plays an important role in the force calculation, affecting both the iceberg motion and tsunamis. To preserve the same iceberg velocity for different resolutions in the convergence tests, the velocity was prescribed using the motion measured in the laboratory experiments (Fig. 12).
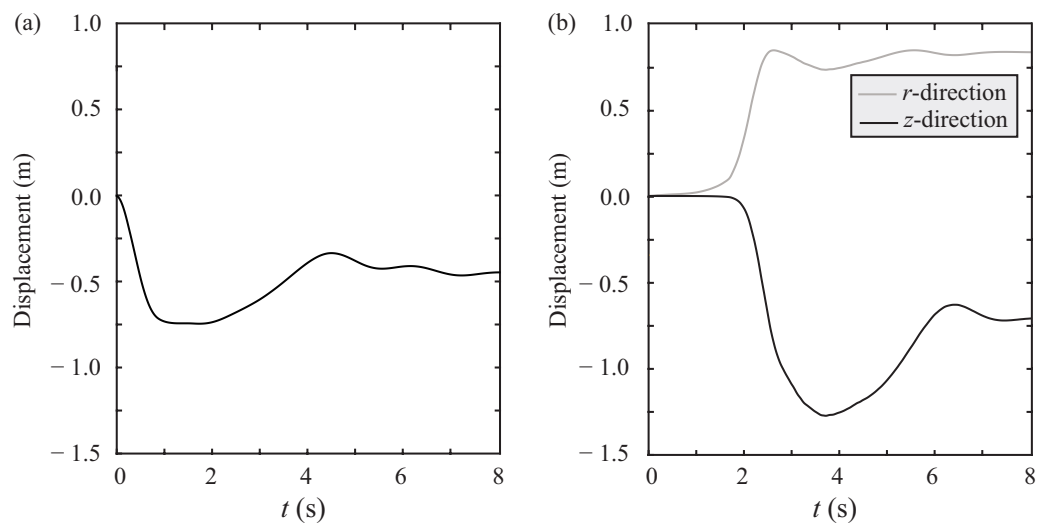

Fig. 12 Displacements in function of time based on the motion sensor data of (a) mechanism $\mathrm{B}$ along the $z$ and (b) mechanism $\mathrm{D}$ along the $r$ - and $z$-directions

All simulations were run on a HPC cluster. The number of cells in the com- 

$8 \mathrm{~h}$ to simulate $5 \mathrm{~s}$ real time for the coarsest and $96 \mathrm{~h}$ for the finest resolution.
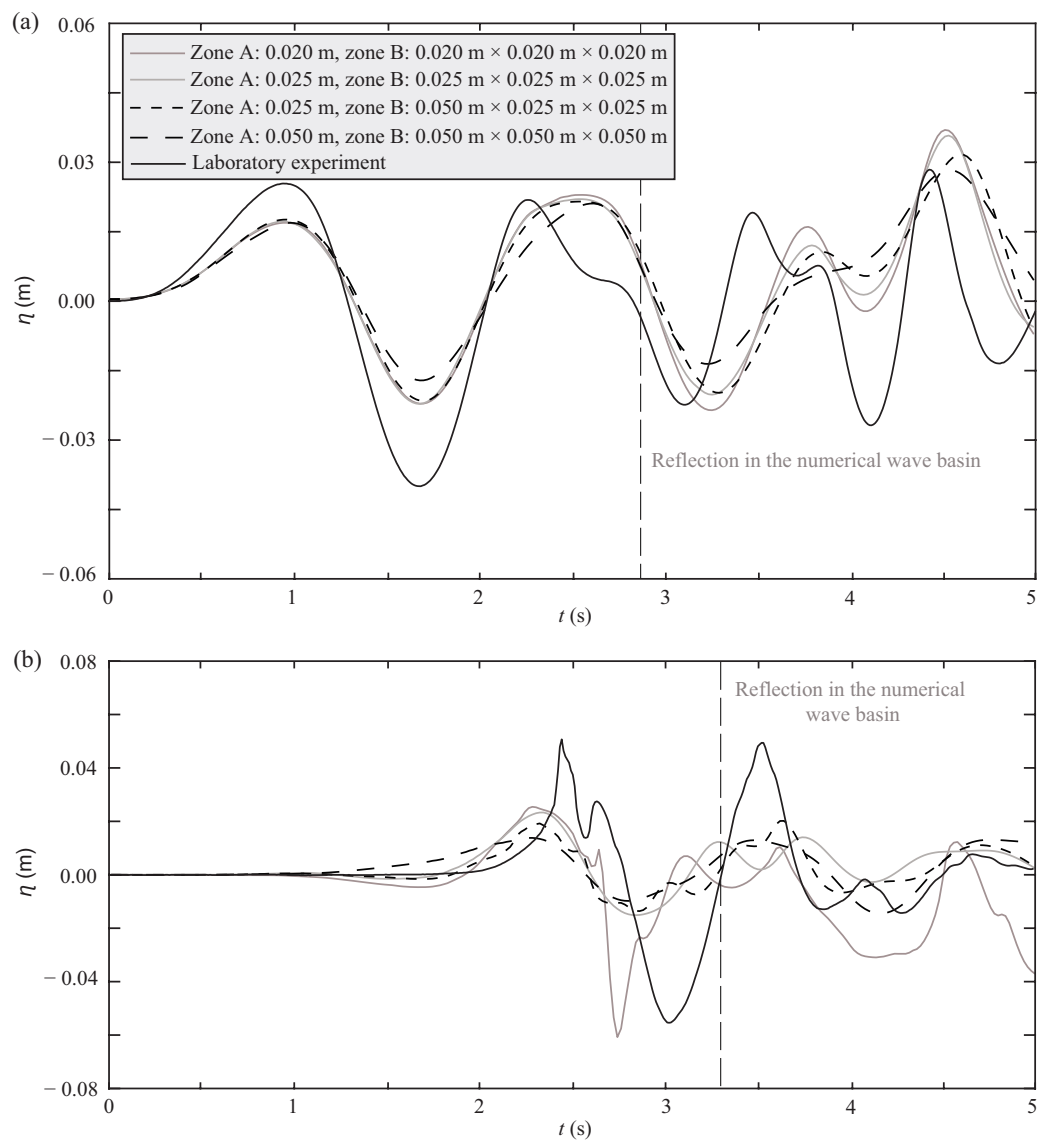

Fig. 13 Convergence tests of (a) mechanism B and (b) mechanism D (for legend see a)

putational domain varied from 0.34 to 5.46 million, and the corresponding cores and memory varied from 3 cores and 4 GB to 30 cores and 36 GB. It required

The wave profiles measured in the convergence tests at wave probe B1 together with the laboratory results are shown in Fig. 13. The convergence tests show that the differences of the first wave amplitude $a_{1}$ between the two closest wave profiles in each mechanism are 0.03 and $0.21 \mathrm{~cm}$, respectively, for resolutions higher than $0.050 \mathrm{~m} \times 0.025 \mathrm{~m} \times 0.025 \mathrm{~m} .0 .025 \mathrm{~m} \times 0.025 \mathrm{~m} \times 0.025$ $\mathrm{m}$ was selected for the main tests for both the IBT generation and propagation zones as a finer resolution did not provide further benefits. Fig. 13 further shows 
that IBTs from the prescribed iceberg motion are always smaller than those observed in the laboratory. This is likely because the interpolation method of this IBM toolbox results in a slight underestimation of the velocity and pressure at the immersed boundary when using the prescribed motion, resulting in smaller waves. A more robust interpolation method or a more accurate immersed boundary representation may help to solve this issue. However, as later demonstrated with Fig. 15, our results are sound despite of this shortcoming.
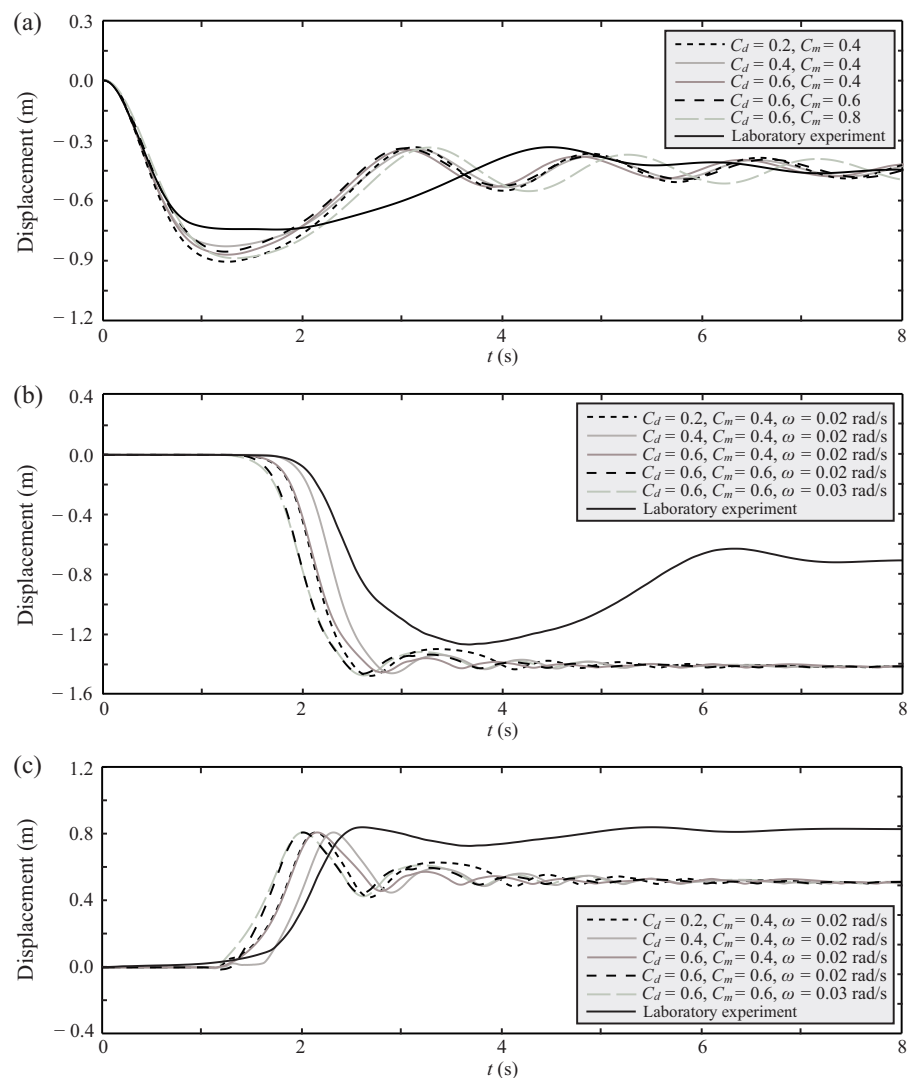

Fig. 14 Iceberg displacements in function of time of (a) mechanism B and (b) vertical and (c) horizontal displacements of mechanism $\mathrm{D}$ with different $C_{d}, C_{m}$ and $\omega$

\subsection{IBTs generated with resolved motion}

The results presented in this section were obtained with resolved iceberg motion and the laminar model was applied. The effect of turbulence is discussed 
in Section 5.1. The computational domain consists of 20,768,000 cells and 54 cores were used. Each test required approximately 50 h to complete $8.0 \mathrm{~s}$ of real time with the domain size shown in Fig. 4.

For mechanism D an initial angular velocity $\omega$ for the iceberg was required to ensure a forward rotation. The time shift of $0.8 \mathrm{~s}$ has been introduced in the numerical time series for the laboratory block to reach a similar $\omega$ as in the numerical simulation. Therefore, in this case, three parameters affect the numerical results: the drag force coefficient $C_{d}$, the added mass coefficient $C_{m}$ and $\omega$, while for mechanism B only $C_{d}$ and $C_{m}$ are relevant. Some indications for the values of $C_{d}$ and $C_{m}$ are given by Lee (1995) for rectangular structures with $0.0<C_{d}<0.6$ and $0.4<C_{m}<0.8$.

Fig. 14 shows the iceberg displacements for different $C_{d}, C_{m}$ and $\omega$ and the corresponding IBTs recorded at wave probe B1 are shown in Fig. 15. Increasing $C_{d}$ and $C_{m}$ reduces the iceberg motion and tsunami heights, and thus the wave celerity. Based on the first wave height $H_{1}$ and amplitude $a_{1}$, the best agreement between the numerical and experimental IBTs is obtained for $C_{d}=0.6$ and $C_{m}$ $=0.4$ for the fall case and $C_{d}=0.6, C_{m}=0.4$ and $\omega=0.02 \mathrm{rad} / \mathrm{s}$ for the overturning case (Fig. 14). The numerically reproduced block motion is always faster than that in the laboratory tests. This may be due to the overestimated underwater volume of the block represented by the IBM resulting in a larger numerical acceleration.

$a_{1}$ is well captured in both calving mechanisms, apart from the large peak of the first wave crest, which is due to the splash in the laboratory experiment (Figs. 11c and 15b). The splash is not fully modelled because of the chosen resolution and the laminar application used. Snapshot series of the simulations of the two mechanisms are shown in Figs. 16 and 17. The numerical results generally agree with the laboratory observations (Figs. 10 and 11). However, only parts of the splash observed in the laboratory tests (Figs. 10b and 11c) are simulated in Figs. 16(b) and 17(b,c). Similarly to the laboratory experiments, the waves propagate then in a semi-circular pattern in Figs. 16(c,d) and 17(c,d) and leave the area of view. 

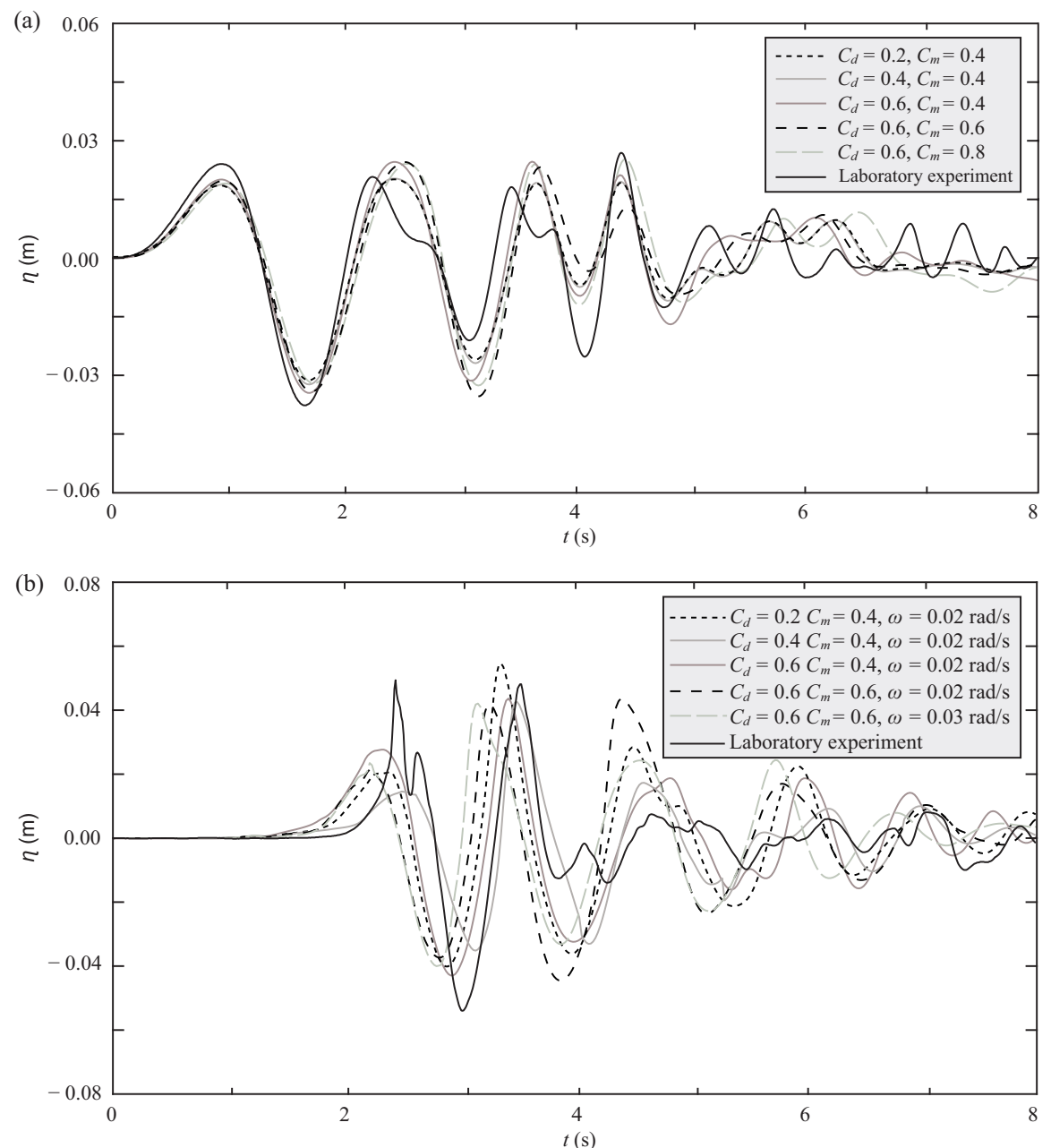

Fig. 15 IBTs involving different $C_{d}, C_{m}$ and $\omega$ for (a) mechanism B and (b) mechanism D

The relative difference between the laboratory and numerical $a_{1}$ is $15.5 \%$ in Fig. 15(a) and $44.5 \%$ in Fig. 15(b). However, if the splash is excluded by using the measured wave amplitude at wave probe B2 (Fig. 4, where no splash occurs) and interpolating this value from $\gamma=15^{\circ}$ to $\gamma=0^{\circ}$ with the term $\cos (\gamma / 2)$ of Eq. (B.10) found in Heller et al. (2020), $a_{1}=0.0294 \mathrm{~m}$ and the difference reduces to $4.8 \%$. Further, the troughs of the first numerical waves are 10.5 and $23.1 \%$, respectively, smaller than in the laboratory experiments. The reason for this underestimation may be that the aforementioned larger numerical acceleration 

faster and it inhibits the growth of the first wave.

(a)

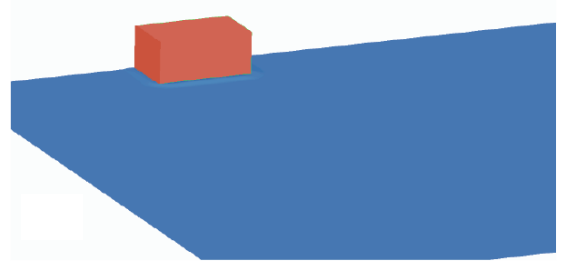

(c)

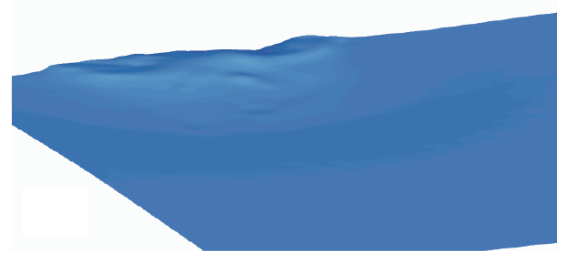

(b)

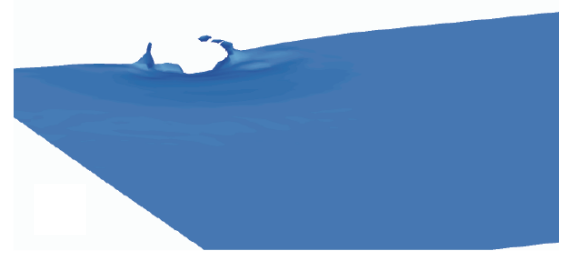

(d)

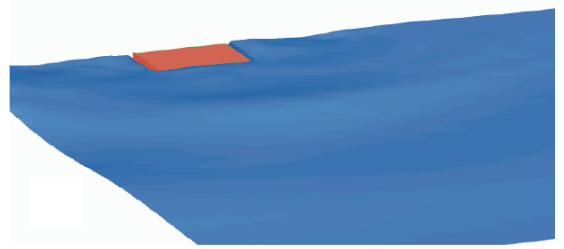

Fig. 16 Snapshots of numerical IBTs generated by mechanism B at (a) $t=0.00 \mathrm{~s}$, (b) $t=$ $1.33 \mathrm{~s},(\mathrm{c}) t=2.67 \mathrm{~s}$ and $(\mathrm{d}) t=4.00 \mathrm{~s}$

(a)

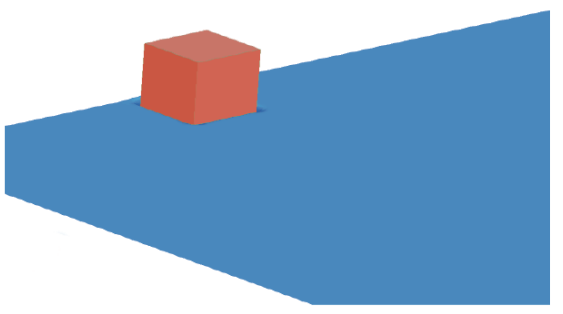

(c)

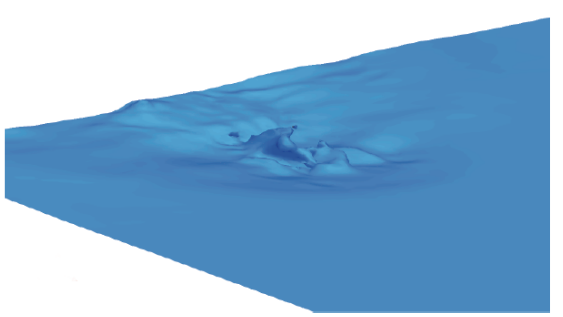

(b)

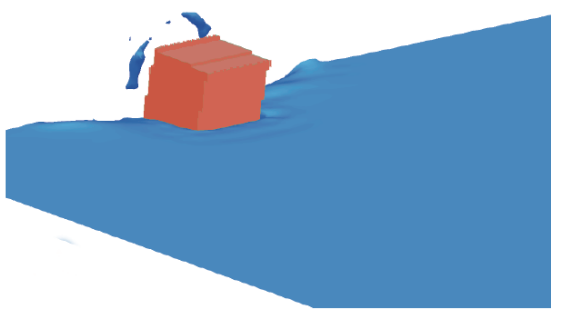

(d)

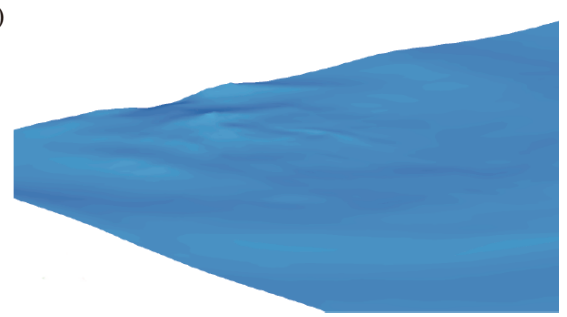

Fig. 17 Snapshots of numerical IBTs generated by mechanism D at (a) $t=0.00 \mathrm{~s}$, (b) $t=$ $1.33 \mathrm{~s},(\mathrm{c}) t=2.67 \mathrm{~s}$ and $(\mathrm{d}) t=4.00 \mathrm{~s}$ 


\subsection{Comparison of numerical and laboratory wave decay}

IBT decay is important for hazard assessment for offshore and coastal structures. Fig. 18 shows the water surface elevation $\eta(t)$ at wave probes B1, B7 and B13 (Table 1) for both the numerical and laboratory models. The wave decay is based on the relative first wave amplitude $a_{1} / h\left(r / h, \gamma=0^{\circ}\right)$, relative height $H_{1} / h\left(r / h, \gamma=0^{\circ}\right)$ and the assumption that the waves decay with a power function in the form $a_{1} / h\left(r / h, \gamma=0^{\circ}\right) \sim(r / h)^{c}$ and $H_{1} / h\left(r / h, \gamma=0^{\circ}\right) \sim(r / h)^{c}$. The results of the comparison between the numerical $\left(c_{n}\right)$ and laboratory $\left(c_{l}\right)$ decay exponents are shown in Table 2 , together with $a_{1} / h\left(r / h, \gamma=0^{\circ}\right)$ and $H_{1} / h\left(r / h, \gamma=0^{\circ}\right)$ of the first wave. Note that $c$ is obtained using the first three wave probes only, which explains the difference from $c_{l}=-1.2$ found by Heller et al. (2020) who used all wave probe data. Table 2 shows that both the numerical wave amplitude and height decay in mechanism B agree well with the laboratory tests with a maximum deviation of $12.0 \%$. However, for mechanism $\mathrm{D}$, the IBTs in the laboratory decay up to $45.8 \%$ faster than in the numerical simulations. This is again due to the larger splash in the laboratory affecting the first wave crest. If $a_{1}=0.0294 \mathrm{~m}$ from Section 4.4 is used, excluding the splash, then $c_{n}$ for the wave amplitude and height decay become $29.0 \%$ and $13.8 \%$ smaller than $c_{l}$, respectively. This removal of the splash is justified as it is of small relevance for the far field wave propagation.

Table 2 Comparison of numerical and laboratory wave decay: $a_{1} / h$ and $H_{1} / h$ measured at wave probes $\mathrm{B} 1, \mathrm{~B} 7$ and $\mathrm{B} 13$ and the numerical $c_{n}$ and laboratory model $c_{l}$ wave decay exponents

\begin{tabular}{|c|c|l|l|l|l|l|l|l|}
\hline \multirow{2}{*}{} & \multicolumn{4}{|c|}{ Mechanism B } & \multicolumn{3}{c|}{ Mechanism D } \\
\cline { 2 - 9 } & \multicolumn{2}{|c|}{$a_{1} / h$} & \multicolumn{2}{c|}{$H_{1} / h$} & \multicolumn{2}{c|}{$a_{1} / h$} & \multicolumn{2}{c|}{$H_{1} / h$} \\
\cline { 2 - 9 } & Lab. & Num. & Lab. & Num. & Lab. & Num. & Lab. & Num. \\
\hline B1 & 0.0238 & 0.0201 & 0.0619 & 0.0541 & 0.0505 & 0.0280 & 0.1064 & 0.0710 \\
\hline B7 & 0.0141 & 0.0116 & 0.0398 & 0.0341 & 0.0112 & 0.0143 & 0.0391 & 0.0366 \\
\hline B13 & 0.0079 & 0.0066 & 0.0232 & 0.0194 & 0.0046 & 0.0077 & 0.0127 & 0.0185 \\
\hline$c_{l}$ or $c_{n}$ & -1.214 & -1.360 & -1.090 & -1.114 & -2.619 & -1.420 & -2.201 & -1.476 \\
\hline$\frac{c_{n}-c_{l}}{c_{l}} \times 100 \%$ & - & $12.0 \%$ & - & $2.2 \%$ & - & $-45.8 \%$ & - & $-32.9 \%$ \\
\hline
\end{tabular}



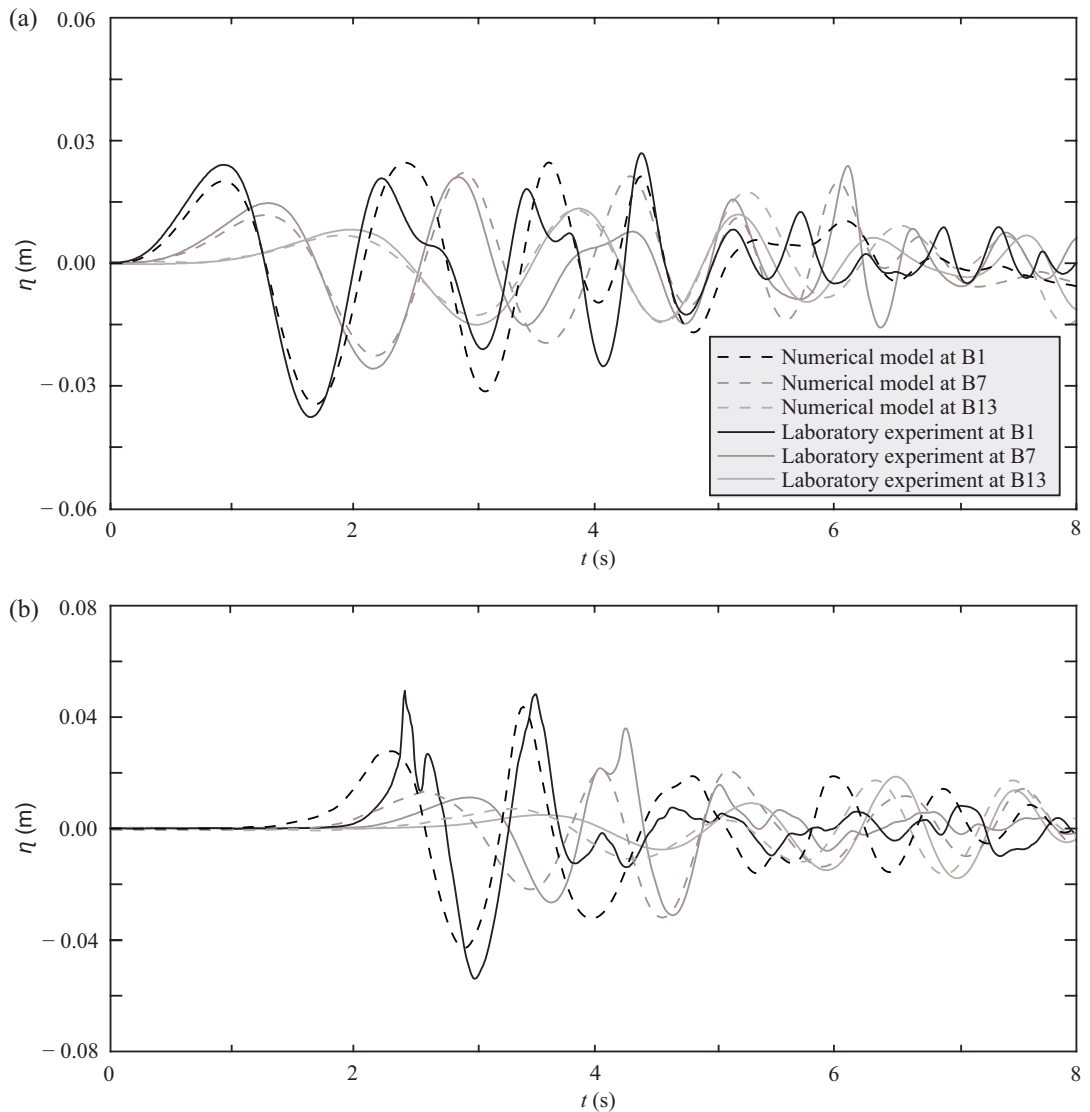

Fig. 18 Water surface elevation $\eta(t)$ at wave probes B1, B7 and B13 in the numerical and laboratory models (for legend see a)

\subsection{Simulation of the 2014 Eqip Sermia case}

The IBT at Eqip Sermia (Lüthi and Vieli, 2016) is simulated in this section. The bathymetric data of Eqip Sermia is available from GEBCO (2019) with a resolution of approximately $160 \mathrm{~m} \times 460 \mathrm{~m}$. A linear interpolation was applied on the raw bathymetry data to obtain a higher resolution of $5 \mathrm{~m} \times 5 \mathrm{~m}$. In order to be consistent with the cell dimension in the convergence tests and the main IBT simulations, a structured mesh with a length scale of 1:100 was then generated based on the processed bathymetry data and the following results are all presented at this scale. Fig. 19(a) shows the Cartesian coordinate system, where $z=0.0 \mathrm{~m}$ corresponds to the sea level and the $x$ - and $y$-axes are parallel 
to the local latitudinal and longitudinal directions, respectively. The numerical domain is $15.0 \mathrm{~m} \times 15.0 \mathrm{~m}$ with heights between 2.45 and $3.15 \mathrm{~m}$ (Fig. 19). The cell dimension is $0.05 \mathrm{~m} \times 0.05 \mathrm{~m} \times 0.05 \mathrm{~m}$. The numerical simulation was run on 4 cores and required $38 \mathrm{~h}$ for $5.0 \mathrm{~s}$ real time. Fig. 20 shows the evolution of the IBT in the impact zone. The topography of the glacier terminus and the geometry of the calving iceberg were obtained from Fig. 3 in Lüthi and Vieli (2016). The iceberg represented by the IBM has a volume of $0.9 \mathrm{~m}^{3}$ (the brown body in Fig. 19). The IBM requires at least a space of 2 cells between the domain boundary and the immersed boundary. This gap between the iceberg and the glacier is likely to reduce the iceberg amplitude as discussed later in Section 4.6.

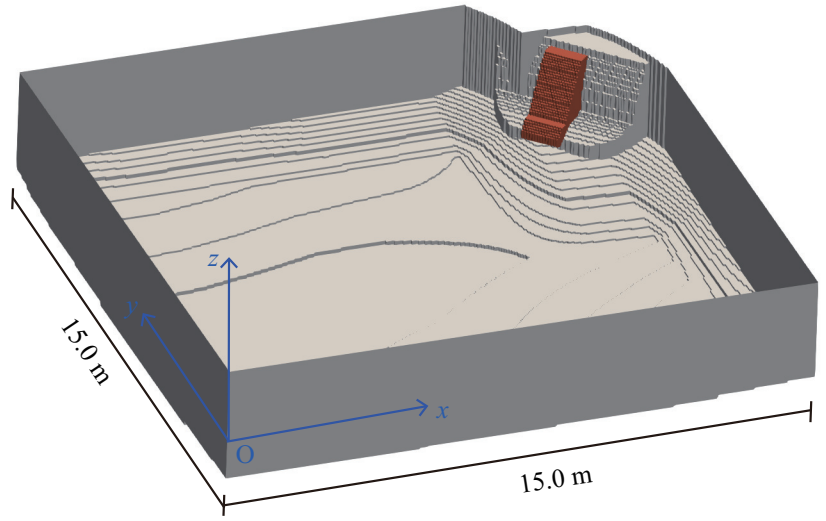

Fig. 19 Computation domain used for the Eqip Sermia case with the calving iceberg represented by the IBM

The motion of the calving iceberg was resolved in this simulation, while the trajectory was restricted to ensure that the iceberg did not touch the domain boundary and the impact velocity of $48.2 \mathrm{~m} / \mathrm{s}$ (which is slightly larger than the estimated value of $42 \mathrm{~m} / \mathrm{s}$ by Lüthi and Vieli, 2016) was imposed after investigating a range of values. The motion was performed in the plane $(x=y, z)$. The iceberg movement was modelled as a combined translation and rotation, which was most likely also observed in nature given the glacier terminus geometry, the iceberg shape and $h=25$ to $45 \mathrm{~m}$ in the impact zone. 
(a)

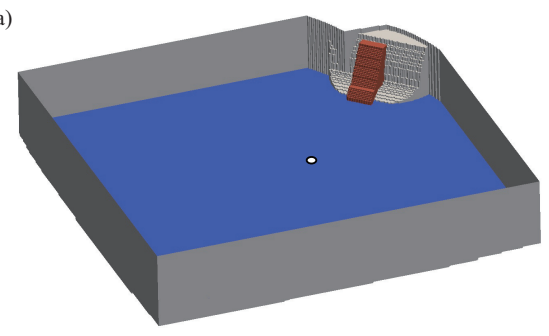

(c)

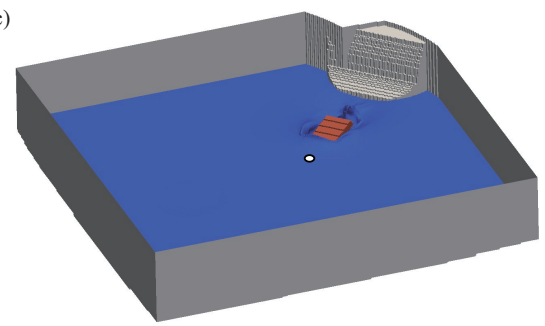

(e)

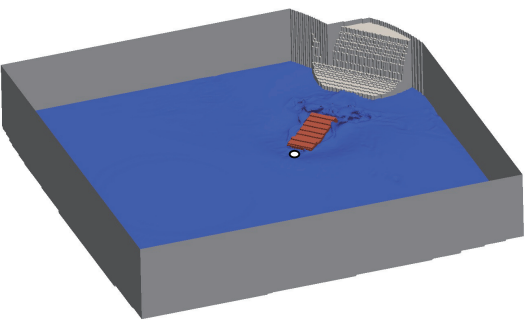

(b)

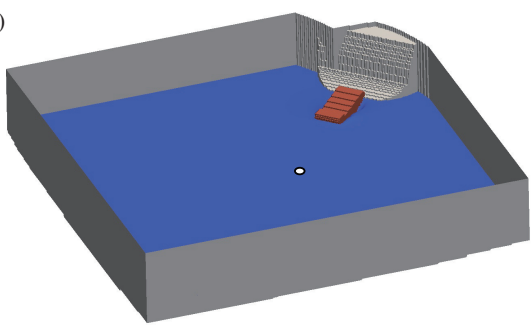

(d)

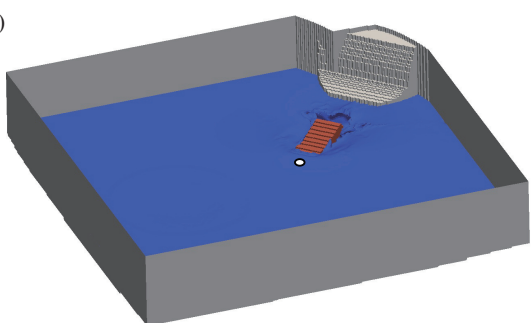

(f)

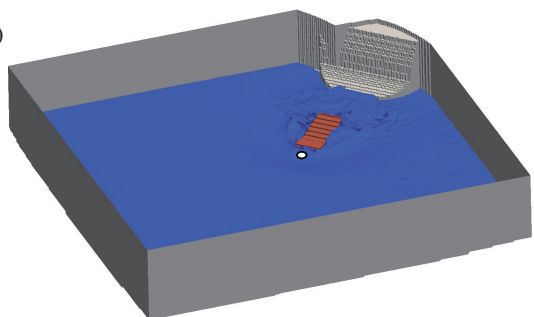

Fig. 20 Snapshots of IBTs in the Eqip Sermia case at a scale 1:100 at (a) $t=0.0 \mathrm{~s},(\mathrm{~b}) t=$ $0.4 \mathrm{~s},(\mathrm{c}) t=0.8 \mathrm{~s}$, (d) $t=1.2 \mathrm{~s}$, (e) $t=1.6 \mathrm{~s}$ and (f) $t=2.0 \mathrm{~s}$. The white circle denotes the wave probe

At $t=0.4 \mathrm{~s}$, the iceberg starts to move along the glacier terminus and reaches the water surface. The iceberg progressively submerges and rotates generating waves (Fig. 20c). The waves continue to grow due to the iceberg at $t=0.8,1.2$ and 1.6 s. In Fig. 20(f) wave run-up on the glacier front can be observed and the iceberg floats backward. In contrast to the real event, no splash or bore is observed due to the selected resolution and the application of the laminar model (Section 4.4).

There were a number of wave probes placed along the direction of the moving iceberg. The maximum measured IBT was observed at $3.80 \mathrm{~m}$ from the glacier terminus and used for further analysis (Fig. 21). $a_{1}$ corresponds to 0.404 
$\mathrm{m}$, which is 10.2 to $19.3 \%$ smaller than the down-scaled observed amplitude. The difference is likely due to the gap between the iceberg and the glacier front reducing the efficiency of the generation of the leading wave. This effect is difficult to estimate, however, Heller and Spinneken (2013) investigated a closely related phenomenon with a rigid mass impacting into a water body and generating a wave with the part of the water in the gap between the mass and the boundary also remaining passive in the wave generation process. Heller and Spinneken (2013) found that a gap of $12 \%$ between a solid slide heavier than water and the side wall in a flume reduces the wave height by approximately the same percentage. Extrapolated to the present results, the gap is $\approx 20 \%$ of the iceberg thickness, which may reduce the wave height by $\approx 20 \%$. The maximum IBT amplitude of $1 /(1-0.2) \times 0.404=0.505 \mathrm{~m}$ would therefore reach the upper value of the observed range. However, the rigidity of the iceberg, which tends to increase the wave amplitude compared to a granular slide under the given conditions, may also play a role (Heller and Spinneken, 2013).

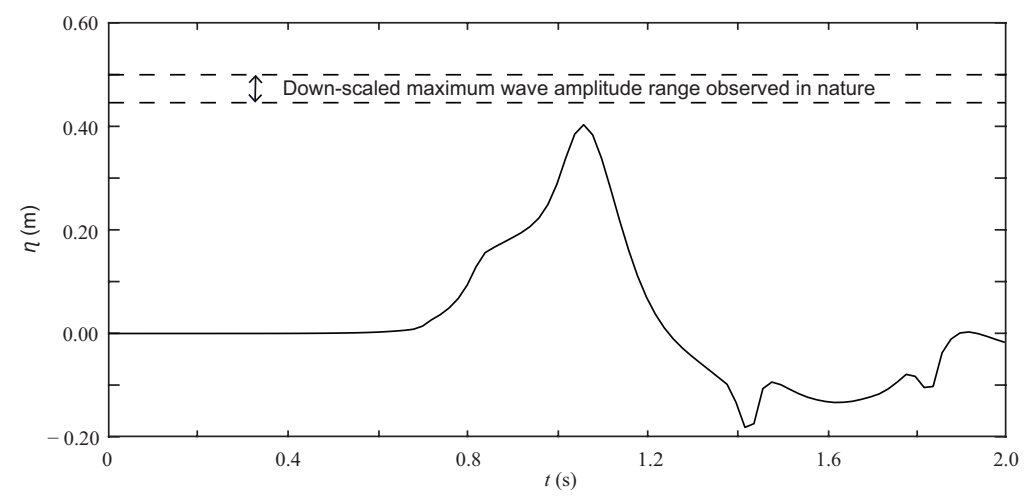

Fig. 21 IBT at scale 1:100 measured $3.80 \mathrm{~m}$ away from the glacier terminus

\section{Discussion of results}

\subsection{Effect of turbulence modelling}

The RANS based $k-\epsilon$ turbulence model is already implemented in the IBM toolkit in Foam-extend 4.0, but some modifications in the boundary conditions 
were necessary. Details about this turbulence model and the necessary modifications can be found in Appendix C. Fig. 22 shows the generated tsunamis of mechanism B including laboratory results together with the corresponding results of the laminar and turbulence model. The simulation with turbulence for the overturning case was also conducted, confirming the findings for the fall case, however, with a worse fit to the laboratory data. Initial values for the turbulent kinetic energy $k$ and the dissipation of the turbulent kinetic energy $\epsilon$ were allocated and then resolved at each time step. The ranges of $k$ and $\epsilon$ in Fig. 22 are $\left[10^{-6}, 0.5\right] \mathrm{m}^{2} / \mathrm{s}^{2}$ and $[0.2,0.8] \mathrm{m}^{2} / \mathrm{s}^{3}$, respectively.

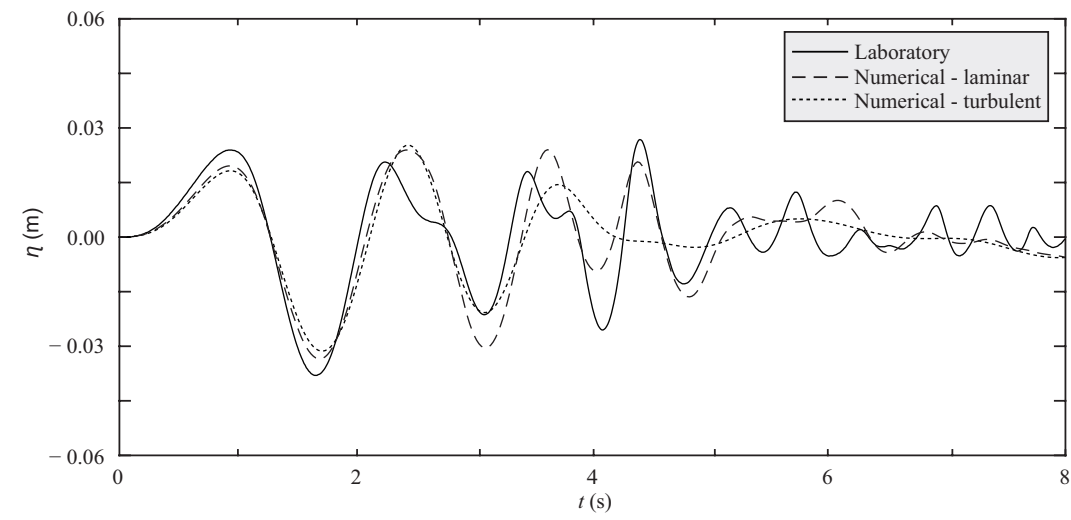

Fig. 22 Comparison of the water surface $\eta(t)$ of mechanism B based on the laboratory test, the laminar model and the turbulence model

As expected, the tsunami including turbulence is smaller than the laminar one. The exponents of the wave height decay power function have also been calculated with a worse fit than the laminar ones (Section 4.5). Given the better agreement of the results for the laminar model and that computational resources can be saved, the IBTs in the main part of Section 4 were modelled without turbulence.

\subsection{Limitations}

The introduced model technique is expected to be useful for many other related applications involving floating bodies such as floating structures and ships in waves. However, there is also some room for improvements. Firstly, the 
dimension of the computational domain is limited (Fig. 4), such that only the first two waves at the first three wave probes were analysed. Secondly, the gap between the iceberg and basin back wall of mechanism D affects IBT generation. Thirdly, more work is required to improve the accuracy of the iceberg motion under water. Lastly, since ensuring zero divergence may cause some disturbance for multiphase flows around the immersed boundary, especially when the iceberg surface frequently interacts with the interface of the multiphase flow. Therefore, the current numerical model requires more work to also simulate small waves, in the order of millimetres at laboratory scale, well.

\section{Conclusions}

This article presented a novel numerical methodology to simulate the generation and propagation of tsunamis generated by calving icebergs. The proposed methodology is based on the solution of flow equations using the Immersed Boundary Method (IBM) in Foam-extend 4.0, validated with one analytical solution and two selected large-scale iceberg-tsunami (IBT) laboratory experiments conducted in a $50 \mathrm{~m} \times 50 \mathrm{~m}$ wave basin. A newly implemented multiphase solver interDyMIbFoam was coupled with a modified motion solver. This enables to handle dynamic immersed boundaries to resolve iceberg motion under a wide range of iceberg calving mechanisms. Coupling between the motion and flow solvers was achieved by simulating the fluid-solid interaction including the calculations of pressure force, viscosity force, drag force and virtual force due to the added mass.

This numerical model is, in principle, capable of simulating all five iceberg calving mechanisms investigated by Heller et al. (2019c; 2020). The model has been validated with an analytical solution of radiated waves from a heaving sphere in still water and with resolved iceberg motion and IBTs of gravitydominated fall (B) and gravity-dominated overturning (D) mechanisms. The results show that the assumption of laminar flow in the simulations leads to better accuracy, outside the splash zone, with less computational resources than simu- 
lations involving a turbulence model. The numerical model underestimates the laboratory IBTs with a maximum of $15.5 \%$ (mechanism B) and $44.5 \%$ (mechanism D, mainly due to the splash) relative to the first (leading) wave amplitude. If the splash is artificially removed by relying on an empirical equation, then the underestimation for mechanism D reduces to $4.8 \%$. This is likely because the iceberg volume under water is overestimated, making it move too fast towards the water surface. For IBT propagation, the numerical wave height power function decay exponent is $2.2 \%$ larger and $13.8 \%$ smaller in mechanism B and D, respectively (Section 4.5), with the effect of the splash excluded for the latter. The numerical model was then used to successfully simulate the 2014 Eqip Sermia case resulting in a good agreement with the observation in nature.

In future work further IBT mechanisms will be simulated. The present model should also be made more computational efficient and the overestimation of the iceberg volume in the IBM should be addressed. Furthermore, the presented model is ready to model other floating bodies such as floating breakwaters, wave energy converters and vessels.

\section{Acknowledgements}

Dr Niels Gjøl Jacobsen is acknowledged for recommending to use the IBM and Dr David Hargreaves is thanked for useful comments. The PhD study of FC was financially supported by the China Scholarship Council (CSC). The laboratory tests were supported by the European Community's Horizon2020 Research and Innovation Programme through the grant to HYDRALAB+, Contract no. 654110. Most simulations were run on Athena at HPC Midlands+, which was funded by EPSRC on grant EP/P020232/1, as part of the HPC Midlands+ consortium. Numerical simulations were also conducted on the University of Nottingham HPC clusters Augusta and Minerva. The raw data of the experiments used herein are available from Heller (2019) with two experiments documented in detail in Chen and Heller (2020). The source code of the new solver is available upon request. 
571 Notation

\begin{tabular}{|c|c|c|}
\hline $\mathbf{a}$ & acceleration vector & {$\left[\mathrm{m} \cdot \mathrm{s}^{-2}\right]$} \\
\hline $\mathbf{a}_{a}$ & global acceleration vector & {$\left[\mathrm{m} \cdot \mathrm{s}^{-2}\right]$} \\
\hline $\mathbf{a}_{l}$ & local acceleration vector & {$\left[\mathrm{m} \cdot \mathrm{s}^{-2}\right]$} \\
\hline$a_{r}$ & sphere radius & {$[\mathrm{m}]$} \\
\hline$a_{1}$ & first wave amplitude & {$[\mathrm{m}]$} \\
\hline$A$ & oscillation amplitude & {$[\mathrm{m}]$} \\
\hline$A_{b}$ & cross section perpendicular to the direction of velocity & {$\left[\mathrm{m}^{2}\right]$} \\
\hline$b$ & block width & {$[\mathrm{m}]$} \\
\hline$c$ & wave decay exponent & {$[-]$} \\
\hline$C$ & complex constant & {$[-]$} \\
\hline$C_{d}$ & drag force coefficient & {$[-]$} \\
\hline$C_{m}$ & added mass coefficient & {$[-]$} \\
\hline$C_{\mu}, C_{1 \epsilon}, C_{2 \epsilon}$ & constants in the turbulence model & {$[-]$} \\
\hline $\mathbf{d}_{C o R}$ & $\begin{array}{l}\text { vector pointing from the immersed boundary cell to } \\
\text { the centre of rotation }\end{array}$ & {$[\mathrm{m}]$} \\
\hline$d_{\mathrm{i}}$ & complex constant series & {$[-]$} \\
\hline $\mathbf{F}$ & total force vector acting on the iceberg & {$\left[\mathrm{kg} \cdot \mathrm{m} \cdot \mathrm{s}^{-2}\right]$} \\
\hline $\mathbf{F}_{d}$ & drag force vector & {$\left[\mathrm{kg} \cdot \mathrm{m} \cdot \mathrm{s}^{-2}\right]$} \\
\hline $\mathbf{F}_{p}$ & pressure force vector & {$\left[\mathrm{kg} \cdot \mathrm{m} \cdot \mathrm{s}^{-2}\right]$} \\
\hline $\mathbf{F}_{v}$ & viscosity force vector & {$\left[\mathrm{kg} \cdot \mathrm{m} \cdot \mathrm{s}^{-2}\right]$} \\
\hline g & gravitational acceleration vector & {$\left[\mathrm{m} \cdot \mathrm{s}^{-2}\right]$} \\
\hline$g$ & gravitational acceleration & {$\left[\mathrm{m} \cdot \mathrm{s}^{-2}\right]$} \\
\hline G & gravity force vector & {$\left[\mathrm{kg} \cdot \mathrm{m} \cdot \mathrm{s}^{-2}\right]$} \\
\hline$h$ & water depth & {$[\mathrm{m}]$} \\
\hline$H_{1}$ & first wave height & {$[\mathrm{m}]$} \\
\hline$i$ & imaginary unit & {$[-]$} \\
\hline$I$ & moment of inertia; integral of Legendre polynomials & {$\left[\mathrm{kg} \cdot \mathrm{m}^{2} ;-\right]$} \\
\hline$J$ & polynomials & {$[-]$} \\
\hline$k$ & turbulent kinetic energy & {$\left[\mathrm{m}^{2} \cdot \mathrm{s}^{-2}\right]$} \\
\hline
\end{tabular}




\begin{tabular}{|c|c|c|}
\hline K & wave number & {$\left[\mathrm{m}^{-1}\right]$} \\
\hline$l$ & block length & {$[\mathrm{m}]$} \\
\hline$m_{a}$ & added mass & {$[\mathrm{kg}]$} \\
\hline$m_{s}$ & iceberg mass & {$[\mathrm{kg}]$} \\
\hline M & total torque in relation to the centre of rotation & {$\left[\mathrm{kg} \cdot \mathrm{m}^{2} \cdot \mathrm{s}^{-2}\right]$} \\
\hline$M_{i j}$ & complex constant series & {$[-]$} \\
\hline N & truncated number of infinite linear system of equations & {$[-]$} \\
\hline $\mathrm{N}_{\mathrm{k}}$ & truncated number of infinite integral upper bound & {$[-]$} \\
\hline$p$ & fluid pressure & {$\left[\mathrm{kg} \cdot \mathrm{m}^{-1} \cdot \mathrm{s}^{-2}\right]$} \\
\hline$p_{\mathrm{i}}$ & complex constant series & {$[-]$} \\
\hline$P$ & Legendre polynomial & {$[-]$} \\
\hline$r$ & radial distance & {$[\mathrm{m}]$} \\
\hline$R$ & $\begin{array}{l}\text { distance between the motion sensor and the centre of } \\
\text { rotation }\end{array}$ & {$[\mathrm{m}]$} \\
\hline$R_{x}, R_{y}, R_{z}$ & rotation matrix relative to the $x-, y$-, $z$-axis & {$[-]$} \\
\hline$s$ & block thickness & {$[\mathrm{m}]$} \\
\hline $\mathbf{S}_{i b}$ & vector of the immersed boundary cell area & {$\left[\mathrm{m}^{2}\right]$} \\
\hline$t$ & time after start of block movement; moment in time & {$[\mathrm{s}]$} \\
\hline $\mathbf{u}$ & fluid velocity vector & {$\left[\mathrm{m} \cdot \mathrm{s}^{-1}\right]$} \\
\hline$u_{x}, u_{y}, u_{z}$ & fluid velocity component along $x$-, $y$-, $z$-axis & {$\left[\mathrm{m} \cdot \mathrm{s}^{-1}\right]$} \\
\hline $\mathbf{v}_{C o M}$ & velocity vector of the centre of mass of the iceberg & {$\left[\mathrm{m} \cdot \mathrm{s}^{-1}\right]$} \\
\hline$V_{x}, V_{y}, V_{z}$ & velocity component along $x-, y-, z$-axis & {$\left[\mathrm{m} \cdot \mathrm{s}^{-1}\right]$} \\
\hline$x$ & horizontal coordinate & {$[\mathrm{m}]$} \\
\hline$x^{\prime}$ & local horizontal coordinate & {$[\mathrm{m}]$} \\
\hline $\mathbf{X}_{C o M}$ & position vector of the centre of mass of the iceberg & {$[\mathrm{m}]$} \\
\hline $\mathbf{X}_{C o R}$ & position vector of the centre of rotation of the iceberg & {$[\mathrm{m}]$} \\
\hline$y$ & coordinate orthogonal to object plane & {$[\mathrm{m}]$} \\
\hline$y^{\prime}$ & local coordinate orthogonal to object plane & {$[\mathrm{m}]$} \\
\hline$z$ & vertical coordinate & {$[\mathrm{m}]$} \\
\hline$z^{\prime}$ & local vertical coordinate & {$[\mathrm{m}]$} \\
\hline
\end{tabular}




\begin{tabular}{|c|c|c|}
\hline$\alpha$ & phase fraction & {$[-]$} \\
\hline$\Delta t$ & time step & {$[\mathrm{s}]$} \\
\hline$\epsilon$ & dissipation of turbulent kinetic energy & {$\left[\mathrm{m}^{2} \cdot \mathrm{s}^{-3}\right]$} \\
\hline$\eta$ & water surface elevation & {$[\mathrm{m}]$} \\
\hline$\gamma$ & wave propagation angle & {$\left[{ }^{\circ}\right]$} \\
\hline$\Gamma$ & Gamma function & {$[-]$} \\
\hline$\lambda$ & Euler-Mascheroni constant & {$[-]$} \\
\hline$\mu$ & dynamic viscosity & {$\left[\mathrm{kg} \cdot \mathrm{m}^{-3}\right]$} \\
\hline$\mu_{t}$ & turbulent viscosity & {$\left[\mathrm{kg} \cdot \mathrm{m}^{-3}\right]$} \\
\hline$\nabla$ & differential operator & {$[-]$} \\
\hline$\omega$ & angular velocity & {$\left[\mathrm{s}^{-1}\right]$} \\
\hline $\boldsymbol{\omega}_{C o R}$ & $\begin{array}{l}\text { angular velocity vector of centre of rotation of the } \\
\text { iceberg }\end{array}$ & {$\left[\mathrm{s}^{-1}\right]$} \\
\hline$\Phi$ & velocity potential & {$\left[\mathrm{m}^{2} \cdot \mathrm{s}^{-1}\right]$} \\
\hline$\phi_{\mathrm{i}}$ & wave-free potential & {$\left[\mathrm{m}^{2} \cdot \mathrm{s}^{-1}\right]$} \\
\hline$\phi_{0}$ & wave source potential & {$\left[\mathrm{m}^{2} \cdot \mathrm{s}^{-1}\right]$} \\
\hline$\pi$ & mathematical constant; $\pi=3.14159$ & {$[-]$} \\
\hline$\psi$ & azimuthal angle & {$\left[{ }^{\circ}\right]$} \\
\hline$\rho$ & fluid density & {$\left[\mathrm{kg} \cdot \mathrm{m}^{-3}\right]$} \\
\hline$\rho_{s}$ & iceberg density & {$\left[\mathrm{kg} \cdot \mathrm{m}^{-3}\right]$} \\
\hline$\sigma$ & angular frequency & {$\left[\mathrm{s}^{-1}\right]$} \\
\hline$\sigma_{\epsilon}$ & constant & {$[-]$} \\
\hline$\sigma_{k}$ & constant & {$[-]$} \\
\hline$\tau_{i b}$ & shear stress & {$\left[\mathrm{kg} \cdot \mathrm{m}^{-1} \cdot \mathrm{s}^{-2}\right]$} \\
\hline$\theta$ & polar angle & {$\left[{ }^{\circ}\right]$} \\
\hline $\boldsymbol{\theta}_{C o R}$ & iceberg rotation angle vector & {$\left[{ }^{\circ}\right]$} \\
\hline$\theta_{x}, \theta_{y}, \theta_{z}$ & yaw, roll, pitch angle & {$\left[^{\circ}\right]$} \\
\hline$\xi$ & angular acceleration vector & {$\left[\mathrm{s}^{-2}\right]$} \\
\hline
\end{tabular}


Subscripts

\begin{tabular}{|c|c|}
\hline$a$ & air; global \\
\hline CoM & Centre of Mass \\
\hline CoR & Centre of Rotation \\
\hline$d$ & drag \\
\hline $\mathrm{i}$ & indexing number \\
\hline$i b$ & immersed boundary \\
\hline $\mathrm{j}$ & indexing number \\
\hline $\mathrm{k}$ & indexing number \\
\hline$l$ & laboratory; local \\
\hline $\mathrm{m}$ & m-order \\
\hline $\max$ & maximum \\
\hline $\min$ & minimum \\
\hline $\mathrm{n}$ & n-order \\
\hline$n$ & numerical \\
\hline $\mathrm{N}$ & maximum indexing number \\
\hline$p$ & pressure \\
\hline$s$ & slide, used for iceberg (adapted from subaerial landslide-tsunami research) \\
\hline$t$ & turbulent \\
\hline$v$ & viscosity \\
\hline$w$ & water \\
\hline$x, y, z$ & $x-, y-, z$-axis \\
\hline 1 & first \\
\hline
\end{tabular}

${ }_{573}$ Abbreviations

$\begin{array}{ll}\text { CoM } & \text { Centre of Mass } \\ \text { CoR } & \text { Centre of Rotation } \\ \text { DoF } & \text { Degree of Freedom } \\ \text { HPC } & \text { High Performance Computing }\end{array}$




$\begin{array}{ll}\text { IBM } & \text { Immersed Boundary Method } \\ \text { IBT } & \text { Iceberg-tsunami } \\ \text { Lab. } & \text { Laboratory } \\ \text { nRMSE } & \text { normalised Root Mean Square Error } \\ \text { Num. } & \text { Numerical } \\ \text { PIMPLE } & \text { Pressure Implicit Splitting Operator (PISO) and Semi-Implicit } \\ & \text { Method for Pressure-Linked Equations (SIMPLE) } \\ \text { RANS } & \text { Reynolds-Averaged Navier Stokes } \\ \text { SPH } & \text { Smoothed Particle Hydrodynamics }\end{array}$




\section{References}

Abadie, S.M., Harris, J.C., Grilli, S.T. and Fabre, R. (2012). Numerical modeling of tsunami waves generated by the flank collapse of the Cumbre Vieja Volcano (La Palma, Canary Islands): tsunami source and near field effects. Journal of Geophysical Research: Oceans, $117(\mathrm{C} 05030)$.

Benn, D.I., Cowton, T., Todd, J. and Luckman, A. (2017). Glacier calving in Greenland. Current Climate Change Reports, 3(4), 282-290.

Benn, D.I., Warren, C.R. and Mottram, R.H. (2007). Calving processes and the dynamics of calving glaciers. Earth-Science Reviews, 82(3-4), 143-179.

Burton, J.C., Amundson, J.M., Abbot, D.S., Boghosian, A., Cathles, L.M., Correa-Legisos, S., Darnell, K.N., Guttenberg, N., Holland, D.M. and MacAyeal, D.R. (2012). Laboratory investigations of iceberg capsize dynamics, energy dissipation and tsunamigenesis. Journal of Geophysical Research: Earth Surface, 117(F01007).

Chen, F. and Heller, V. (2020). Large-scale iceberg-tsunami benchmark test cases. SPH benchmark test case, SPH European Research Interest Community SPHERIC website (online http://spheric-sph.org/validation-tests, under review).

Depoorter, M.A., Bamber, J.L., Griggs, J.A., Lenaerts, J.T.M., Ligtenberg, S.R., Van den Broeke, M.R. and Moholdt, G. (2013). Calving fluxes and basal melt rates of Antarctic ice shelves. Nature, 502(7469), 89-92.

Dullweber, A., Leimkuhler, B. and McLachlan, R. (1997). Symplectic splitting methods for rigid body molecular dynamics. The Journal of Chemical Physics, 107(15), 5840-5851.

Enet, F. and Grilli, S.T. (2007). Experimental study of tsunami generation by threedimensional rigid underwater landslides. Journal of Waterway, Port, Coastal, and Ocean Engineering, 133(6), 442-454.

Evers, F.M. and Hager, W.H. (2016). Spatial impulse waves: wave height decay experiments at laboratory scale. Landslides, 13(6), 1395-1403.

GEBCO (2019). GEneral Bathymetric Chart of the Oceans. Available online: https://www. gebco.net/data_and_products/gridded_bathymetry_data/ (accessed on 14 May 2020).

Grilli, S.T. and Watts, P. (2005). Tsunami generation by submarine mass failure. I: modeling, experimental validation, and sensitivity analyses. Journal of Waterway, Port, Coastal, and Ocean Engineering, 131(6), 283-297. 
Hadžić, I., Hennig, J., Perić, M. and Xing-Kaeding, Y. (2005). Computation of flow-induced motion of floating bodies. Applied Mathematical Modelling, 29(12), 1196-1210.

Heller, V. (2019). Tsunamis due to ice masses: different calving mechanisms and linkage to landslide-tsunamis. Data storage report of HYDRALAB + test campaign, online under http://doi.org/10.5281/zenodo.2556614.

Heller, V., Attili, T., Chen, F., Brühl, M., Gabl, R., Chen, X., Wolters, G. and Fuchs, H. (2019a). Large-scale experiments of tsunamis generated by iceberg calving. $38^{\text {th }}$ IAHR World Congress, 5628-5639.

Heller, V., Attili, T., Chen, F., Brühl, M., Gabl, R., Chen, X., Wolters, G. and Fuchs, H. (2019b). Large-scale iceberg-tsunami experiments. Proceedings of the HYDRALAB+ Joint User Meeting, Bucharest, Romania, 67-77, Henry, P.-Y., Breteler, M.K. eds.

Heller, V., Atilli, T., Chen, F., Gabl, R. and Wolters, G. (2020). Large-scale investigation into iceberg-tsunamis generated by various iceberg calving mechanisms. Coastal Engineering (minor revision).

Heller, V., Bruggemann, M., Spinneken, J. and Rogers, B.D. (2016). Composite modelling of subaerial landslide-tsunamis in different water body geometries and novel insight into slide and wave kinematics. Coastal Engineering, 109, 20-41.

Heller, V., Chen, F., Brühl, M., Gabl, R., Chen, X., Wolters, G. and Fuchs, H. (2019c). Largescale experiments into the tsunamigenic potential of different iceberg calving mechanisms. Scientific Reports, 9, 861.

Heller, V. and Hager, W.H. (2010). Impulse product parameter in landslide generated impulse waves. Journal of Waterway, Port, Coastal, and Ocean Engineering, 136(3), 145-155.

Heller, V. and Spinneken, J. (2013). Improved landslide-tsunami prediction: effects of block model parameters and slide model. Journal of Geophysical Research: Oceans, 118(3), 14891507.

Heller, V. and Spinneken, J. (2015). On the effect of the water body geometry on landslidetsunamis: physical insight from laboratory tests and 2D to 3D wave parameter transformation. Coastal Engineering, 104(10), 113-134.

Hulme, A. (1982). The wave forces acting on a floating hemisphere undergoing forced periodic oscillations. Journal of Fluid Mechanics, 121, 443-463.

Jasak, H. (2009). OpenFOAM: open source CFD in research and industry. International Journal of Naval Architecture and Ocean Engineering, 1(2), 89-94. 
Jasak, H., Jemcov, A. and Tuković, Z̆. (2007). September. OpenFOAM: a C++ library for complex physics simulations. In International Workshop on Coupled Methods in Numerical Dynamics, 1000, 1-20. IUC Dubrovnik, Croatia.

Jasak, H, Rigler, D. and Tuković, Z̆. (2014). Design and implementation of Immersed Boundary Method with discrete forcing approach for boundary conditions. In $6^{\text {th }}$ European Conference on Computational Fluid Dynamics, ECFD 2014. International Center for Numerical Methods in Engineering, 5319-5332, Barcelona, Spain.

Kamath, A., Chella, M.A., Bihs, H. and Arntsen, Ø.A. (2016). Breaking wave interaction with a vertical cylinder and the effect of breaker location. Ocean Engineering, 128, 105-115.

Lee, J.F. (1995). On the heave radiation of a rectangular structure. Ocean Engineering, 22(1), 19-34.

Levermann, A. (2011). When glacial giants roll over. Nature, 472(7341), 43-44.

Lüthi, M.P. and Vieli, A. (2016). Multi-method observation and analysis of a tsunami caused by glacier calving. The Cryosphere, 10(3), 995-1002.

MacAyeal, D.R., Abbot, D.S. and Sergienko, O.V. (2011). Iceberg-capsize tsunamigenesis. Annals of Glaciology, 52(58), 51-56.

Marshall, J., Adcroft, A., Hill, C., Perelman, L. and Heisey, C. (1997). A finite-volume, incompressible Navier Stokes model for studies of the ocean on parallel computers. Journal of Geophysical Research: Oceans, 102(C3), 5753-5766.

Mei, C.C. (1989). The applied dynamics of ocean surface waves. World scientific, Singapore. Mendsonboaz (2009). Tsunami Greenland - Tsunami Groelândia 1995. Online under https:// www.youtube.com/watch?v=z8LWSOPwkn8 (accessed on 14 May 2020, in German).

Minowa, M., Podolskiy, E., Sugiyama, S., Sakakibara, D. and Skvarca, P. (2018). Glacier calving observed with time-lapse imagery and tsunami waves at Glaciar Perito Moreno, Patagonia. Journal of Glaciology, 64(245), 362-376.

Monaghan, J.J. and Kos, A. (2000). Scott Russell's wave generator. Physics of Fluids, 12(3), 622-630.

Newman, J.N. (2018). Marine hydrodynamics. MIT Press, Cambridge, MA.

OpenFOAM extensions (2016). Online under https://sourceforge.net/u/hjasak/foam-extend4.0/ci/master/tree/ (accessed on 14 May 2020). 
Palacios, F., Colonno, M.R., Aranake, A.C., Campos, A., Copeland, S.R., Economon, T.D., Lonkar, A.K., Lukaczyk, T.W., Taylor, T.W.R. and Alonso, J.J. (2013). Stanford University unstructured (SU2): An open-source integrated computational environment for multiphysics simulation and design. In $51^{\text {st }}$ AIAA Aerospace Sciences Meeting including the New Horizons Forum and Aerospace Exposition, Grapevine, USA.

Panizzo, A., De Girolamo, P. and Petaccia, A. (2005). Forecasting impulse waves generated by subaerial landslides. Journal of Geophysical Research: Oceans, 110(C12025).

Ruffini, G., Heller, V. and Briganti, R. (2019). Numerical modelling of landslide-tsunami propagation in a wide range of idealised water body geometries. Coastal Engineering, 153, 103518.

Tan, H., Ruffini, G., Heller, V. and Chen, S. (2018). A numerical landslide-tsunami hazard assessment technique applied on hypothetical scenarios at Es Vedrà, offshore Ibiza. Journal of Marine Science and Engineering, 6(4), 111, 1-22.

The Guardian (2018). Huge iceberg threatens tiny Greenland village. Online under https://www.theguardian.com/world/2018/jul/14/huge-iceberg-threatens-village-ingreenland (accessed on 14 May 2020).

Vacondio, R., Rogers, B.D., Stansby, P.K., Mignosa, P. and Feldman, J. (2013). Variable resolution for SPH: a dynamic particle coalescing and splitting scheme. Computer Methods in Applied Mechanics and Engineering, 256, 132-148.

Vaňková, I. and Holland, D.M. (2016). Calving signature in ocean waves at Helheim Glacier and Sermilik Fjord, East Greenland. Journal of Physical Oceanography, 46(10), 2925-2941.

Violeau, D. and Rogers, B.D. (2016). Smoothed particle hydrodynamics (SPH) for free-surface flows: past, present and future. Journal of Hydraulic Research, 54(1), 1-26.

Weller, H.G., Tabor, G., Jasak, H. and Fureby, C. (1998). A tensorial approach to computational continuum mechanics using object-oriented techniques. Computers in Physics, 12(6), $620-631$. 
703

704

\section{Appendix A: Trajectory inference using the motion sensor}

The trajectory inference method presented here applies to all five iceberg calving mechanisms investigated by Heller et al. (2019c; 2020). The motion sensor includes three sensors: a gyroscope, an accelerometer and a geomagnetic sensor. To obtain the block trajectories, only the gyroscope and accelerometer are required. Three global angles and three local accelerations along three local axes were recorded, which were converted from local to global coordinates as presented hereafter.

The following three standard rotation matrices rotate vectors by an angle $\theta$ relative to the $x-, y$, and $z$-axes, respectively.

$$
R_{x}\left(\theta_{x}\right)=\left[\begin{array}{ccc}
1 & 0 & 0 \\
0 & \cos \theta_{x} & -\sin \theta_{x} \\
0 & \sin \theta_{x} & \cos \theta_{x}
\end{array}\right]
$$

$$
R_{y}\left(\theta_{y}\right)=\left[\begin{array}{ccc}
\cos \theta_{y} & 0 & \sin \theta_{y} \\
0 & 1 & 0 \\
-\sin \theta_{y} & 0 & \cos \theta_{y}
\end{array}\right]
$$

$$
R_{z}\left(\theta_{z}\right)=\left[\begin{array}{ccc}
\cos \theta_{z} & -\sin \theta_{z} & 0 \\
\sin \theta_{z} & \cos \theta_{z} & 0 \\
0 & 0 & 1
\end{array}\right]
$$

The global acceleration along three axes can thus be obtained by using matrix multiplication as

$$
\mathbf{a}_{a}=\left[R_{z}\left(\theta_{z}\right) R_{y}\left(\theta_{y}\right) R_{x}\left(\theta_{x}\right)\right]^{-1} \mathbf{a}_{l}+\mathbf{g} .
$$

In Eq. (A.2), $\mathbf{a}_{a}$ denotes the global acceleration vector, $\mathbf{a}_{l}$ the local acceleration vector obtained from the accelerometer, $\theta_{x}, \theta_{y}$ and $\theta_{z}$ are the three global an- 
gles recorded with the gyroscope and $\mathbf{g}=(0,0,-9.81) \mathrm{ms}^{-2}$. By integrating the global acceleration once and twice, the velocity and displacement can be obtained, respectively.

A low-pass filter with cut-off frequency of $10 \mathrm{~Hz}$ was applied before dataprocessing to remove noise. Note that in the overturning mechanism the icebergs performed a pure rotational motion. This would have resulted in the accumulation of small errors from three global angles and local accelerations with time. To avoid this, only the global angle $\theta_{x}$ was used for the overturning mechanisms to calculate the velocity components $V_{y}$ and $V_{z}$ with

$$
V_{y}=-R \frac{d \theta_{x}}{d t} \cos \theta_{x}
$$

$$
V_{z}=-R \frac{d \theta_{x}}{d t} \sin \theta_{x}
$$

In Eqs. (A.3) and (A.4), $R$ is the distance between the motion sensor and the centre of rotation (rod), and a central difference scheme was adopted to calculate $\frac{d \theta_{x}}{d t}$ as

$$
\left(\frac{d \theta_{x}}{d t}\right)_{t=t_{\mathrm{n}}}=\frac{1}{2}\left(\frac{\theta_{x}{ }^{\mathrm{n}}-\theta_{x}{ }^{\mathrm{n}-1}}{t^{\mathrm{n}}-t^{\mathrm{n}-1}}+\frac{\theta_{x}{ }^{\mathrm{n}+1}-\theta_{x}{ }^{\mathrm{n}}}{t^{\mathrm{n}+1}-t^{\mathrm{n}}}\right),
$$

where the superscript $n+1, n$ and $n-1$ denote the next, current and previous moments in time, respectively.

\section{Appendix B: Implementation of the solution of the theoretical floating} heaving sphere case

The theory of the floating heaving sphere is based on Hulme (1982) and was implemented in Matlab. In order to solve the unknown complex constant series $p_{\mathrm{i}}$, which is used to determine the complex constant $C$ and velocity potential $\Phi$, $p_{\mathrm{i}}$ needs to satisfy the infinite linear system of equations

$$
p_{\mathrm{i}}+\left(\frac{\sigma^{2}}{g} a_{r}\right) \sum_{\mathrm{j}=1}^{\infty} p_{\mathrm{i}} M_{\mathrm{ij}} i=d_{\mathrm{i}}(\mathrm{i}=1,2,3, \ldots)
$$


734

738

Further, the notation $K=\frac{\sigma^{2}}{g}$ and $I(\mathrm{~m}, \mathrm{n} ; 0)=\int_{0}^{1} P_{\mathrm{m}}(x) P_{\mathrm{n}}(x) d x$ is adopted, where $K$ is the wave number and $P_{\mathrm{m}}(x)$ and $P_{\mathrm{n}}(x)$ are $\mathrm{m}$ - and n-order Legendre polynomials, respectively. In Eq. (B.1), $g$ is the gravitational acceleration, $\sigma$ the angular frequency and $a_{r}$ the sphere radius.

$$
M_{\mathrm{ij}}=\frac{4 \mathrm{i}+1}{2 \mathrm{i}+1}[I(2 \mathrm{i}, 2 \mathrm{j}-1 ; 0)-2 I(2 \mathrm{i}, 1 ; 0) I(0,2 \mathrm{j}-1 ; 0)],
$$

$$
d_{\mathrm{i}}=\frac{4 \mathrm{i}+1}{2 \mathrm{i}+1}\left[J\left(2 \mathrm{i}, K a_{r}\right)-2 J\left(0, K a_{r}\right) I(2 \mathrm{i}, 1 ; 0)\right]
$$

where

$$
\begin{aligned}
J\left(\mathrm{~m}, K a_{r}\right)= & -I(\mathrm{~m}, 0 ; 0)-K a_{r} \sum_{\mathrm{n}=1}^{\infty} \frac{-K a_{r}{ }^{\mathrm{n}}}{(\mathrm{n}-1) !} \frac{\partial}{\partial \mathrm{j}}[I(\mathrm{~m}, \mathrm{j} ; 0)]_{\mathrm{j}=\mathrm{n}} \\
& +K a_{r} \sum_{\mathrm{n}=1}^{\infty} \frac{-K a_{r}{ }^{\mathrm{n}}}{\mathrm{n} !}\left\{\mathrm{n}\left[\Gamma(\mathrm{n}+1)+\pi i-\ln \left(K a_{r}\right)\right]-1\right\} I(\mathrm{~m}, \mathrm{n} ; 0) .
\end{aligned}
$$

$$
I(2 \mathrm{i}, 2 \mathrm{j}-1 ; 0)=\left(\frac{-1}{4}\right)^{\mathrm{i}+\mathrm{j}-1} \frac{(2 \mathrm{i}) !(2 \mathrm{j}-1) !}{(2 \mathrm{i}-2 \mathrm{j}-3)(2 \mathrm{i}+2 \mathrm{j}-2)(\mathrm{i} ! \mathrm{j} !)^{2}}
$$

when $\mathrm{n}$ is an odd number

$$
\begin{aligned}
\frac{\partial}{\partial \mathrm{j}}[I(\mathrm{~m}, \mathrm{j} ; 0)]_{\mathrm{j}=\mathrm{n}}= & \frac{-1 \frac{\mathrm{m}+\mathrm{n}+1}{2}}{4 \frac{\mathrm{m}+\mathrm{n}-1}{2}} \frac{\mathrm{m} !}{\left[\left(\frac{\mathrm{m}}{2}\right) !\right]^{2}} \frac{\mathrm{n} !}{(\mathrm{m}-\mathrm{n})(\mathrm{m}+\mathrm{n}+1)} \frac{1}{\left[\left(\frac{\mathrm{n}-1}{2}\right) !\right]^{2}}\left[\frac{\pi}{2}-\ln 2\right. \\
& \left.+\frac{\Gamma(\mathrm{n}+1)(\mathrm{m}-\mathrm{n})(\mathrm{m}+\mathrm{n}+1)+2 \mathrm{n}+1}{(\mathrm{~m}-\mathrm{n})(\mathrm{m}+\mathrm{n}+1)}-\Gamma\left(\frac{\mathrm{n}+1}{2}\right)\right],
\end{aligned}
$$

and when $\mathrm{n}$ is an even number

$$
\frac{\partial}{\partial \mathrm{j}}[I(\mathrm{~m}, \mathrm{j} ; 0)]_{\mathrm{j}=\mathrm{n}}= \begin{cases}0, & \mathrm{n} \neq \mathrm{m} \\ \frac{-4}{(4 \mathrm{n}+1)^{2}}, & \mathrm{n}=\mathrm{m} .\end{cases}
$$

All components in Eq. (B.1) can now be calculated. In order to solve Eq. (B.1), a truncated finite $\mathrm{N} \times \mathrm{N}$ system of equations was used (here $\mathrm{N}=20$ ). 
752

After the complex constant series $p_{\mathrm{i}}$ is known, $C$ is given by

$$
C=\frac{1}{2}\left[J\left(0, K a_{r}\right)-K a_{r} \sum_{\mathrm{i}=1}^{\mathrm{N}} p_{\mathrm{i}} I(0,2 \mathrm{i}-1 ; 0)\right]^{-1} .
$$

The velocity potential $\Phi$ can now be fully determined. In Eq. (13),

$$
\phi_{0}=\int_{0}^{\mathrm{N}_{\mathrm{k}}} \frac{\mathrm{k}}{\mathrm{k}-K} J_{0}(\mathrm{k} r) d \mathrm{k}
$$

$$
\phi_{\mathrm{i}}=\frac{K}{2 \mathrm{i}} \frac{1}{r^{2 \mathrm{i}}} P_{2 \mathrm{i}-1}(0)+\frac{1}{r^{2 \mathrm{i}+1}} P_{2 \mathrm{i}}(0)
$$

where $\mathrm{N}_{\mathrm{k}}=500$ was selected and $r$ is the radial distance.

\section{Appendix C: Turbulence model in the Foam-extend IBM toolkit}

The RANS equations are introduced in Section 3.1. In order to calculate the turbulent viscosity $\mu_{t}$ in Eq. (2), the following equations for the turbulent kinetic energy $k$ and the dissipation of the turbulent kinetic energy $\epsilon$ need to be solved:

$$
\rho k+\frac{\partial}{\partial x_{\mathrm{i}}}\left(\rho u_{\mathrm{i}} k\right)=\frac{\partial}{\partial x_{\mathrm{i}}}\left(\frac{\mu_{t}}{\sigma_{k}} \frac{\partial k}{\partial x_{\mathrm{i}}}\right)+\mu_{t}\left(\frac{\partial u_{\mathrm{i}}}{\partial x_{\mathrm{j}}}+\frac{\partial u_{\mathrm{j}}}{\partial x_{\mathrm{i}}}\right) \frac{\partial u_{\mathrm{i}}}{\partial x_{\mathrm{j}}}-\rho \epsilon
$$

$$
\rho \epsilon+\frac{\partial}{\partial x_{\mathrm{i}}}\left(\rho u_{\mathrm{i}} \epsilon\right)=\frac{\partial}{\partial x_{\mathrm{i}}}\left(\frac{\mu_{t}}{\sigma_{\epsilon}} \frac{\partial \epsilon}{\partial x_{\mathrm{i}}}\right)+C_{1 \epsilon} \frac{\epsilon}{k} \mu_{t}\left(\frac{\partial u_{\mathrm{i}}}{\partial x_{\mathrm{j}}}+\frac{\partial u_{\mathrm{j}}}{\partial x_{\mathrm{i}}}\right) \frac{\partial u_{\mathrm{i}}}{\partial x_{\mathrm{j}}}-C_{2 \epsilon} \rho \frac{\epsilon^{2}}{k} .
$$

$\mu_{t}$ is then obtained with

$$
\mu_{t}=\rho C_{\mu} \frac{k^{2}}{\epsilon}
$$

Eqs. (1), (2) and (C.1) to (C.3) include five unknown variables to be solved, namely the velocity $u_{i}(\mathrm{i}=x, y, z)$, density $\rho, k, \epsilon$ and $\mu_{t}$, and the five constants $C_{1 \epsilon}=1.44, C_{2 \epsilon}=1.92, C_{\mu}=0.09, \sigma_{k}=1.0$ and $\sigma_{\epsilon}=1.3$.

Note that the original $k-\epsilon$ turbulence model in Foam-extend 4.0 is based on the velocity boundary condition immersedBoundary Velocity WallFunction. However, this boundary condition involves a function correcting the velocity of the immersed boundary, such that it differs from the velocity of the block. Further, 
these corrected boundary velocities resulted in unphysical numerical oscillations in the pressure force. These shortcomings resulted in larger tsunamis than measured in the laboratory. Therefore, the immersedBoundaryVelocityWallFunction 764 was modified to use the same velocity boundary calculation method (quadratic 765 interpolation) as the immersedBoundary in this work. 